\title{
Robust Direct Torque Control with Super-Twisting Sliding Mode Control for an Induction Motor Drive
}

\author{
Saber Krim $\mathbb{D}^{1,2}$ Soufien Gdaim, ${ }^{3,4}$ and Mohamed Faouzi Mimouni, \\ ${ }^{1}$ Research Unit "Industrial Systems Study and Renewable Energy", University of Monastir, Tunisia \\ ${ }^{2}$ The National Engineering School of Monastir, Ibn El jazzar City, 5019 Monastir, Tunisia \\ ${ }^{3}$ Laboratory of Electronics and Microelectronics, Faculty of Sciences, University of Monastir, Tunisia \\ ${ }^{4}$ High Institute of Informatics, University of Monastir, Tunisia \\ Correspondence should be addressed to Saber Krim; krim.saber.enim@gmail.com
}

Received 22 January 2019; Revised 9 May 2019; Accepted 15 May 2019; Published 24 June 2019

Academic Editor: Yongping Pan

Copyright (C) 2019 Saber Krim et al. This is an open access article distributed under the Creative Commons Attribution License, which permits unrestricted use, distribution, and reproduction in any medium, provided the original work is properly cited.

\begin{abstract}
A field-programmable gate array- (FPGA-) based nonlinear Direct Torque Control (DTC) associated with Space Vector Modulation (SVM), Input-Output Feedback Linearization (IOFL), and second-order super-twisting speed controller is proposed to control an induction motor drive. First, the nonlinear IOFL is proposed to achieve a decoupled flux and torque control and the SVM technique is used to control the inverter switching frequency which reduces the torque ripples and noise. Next, to enhance the speed regulation, a super-twisting speed controller is added to an SVM-DTC-IOFL scheme. The nonlinear SVM-DTC-IOFL ensures a high dynamic response, good robustness under the external load disturbances. The Lyapunov theory is used to analyze the system stability. Then, this paper presents the interest of implementing the suggested SVM-DTC-IOFL using a Field-Programmable Gate Array (FPGA) circuit. The main interest of the FPGA-implementation is the reduction of the control loop delay, which is evaluated to a few microseconds, thanks to the parallel processing offered by the FPGA. The performances of the proposed control algorithm are investigated by digital simulation using the Xilinx system generator tool and an experimental implementation utilizing an FPGAVirtex-5-ML507.
\end{abstract}

\section{Introduction}

The Direct Torque Control (DTC) of AC machines was proposed by Takahashi and Noguchi in 1986 [1] and then by Depenbrock in 1988 [2]. Relative to the Field Oriented Control (FOC) strategy, the DTC has taken the attention of several researchers because of its many advantages, like the simple structure, the fast dynamic response, and the less dependence on machine parameters. The main problems of the conventional DTC are torque and the flux ripples, the current distortions, and the variation in the switching frequency. It is well known that the source of the switching frequency variations is the existence of hysteresis comparators in the conventional DTC scheme [3].

To overcome DTC drawbacks, several methods were proposed, such as using extended switching tables, or artificial intelligence techniques $[4,5]$. The Space Vector Modulation (SVM) strategy has been also proposed and developed by several researchers to reduce the torque and the flux ripples by an operation with a constant switching frequency of the inverter. In the SVM-DTC the two hysteresis controllers are replaced by two Proportional Integral (PI) controllers to calculate the reference voltage vector components, which will be modulated by the SVM unit to generate the inverter switching states [6]. This control scheme improves the DTC performances in terms of ripples. However, the use of PI controllers requires the knowledge of the exact model of the controlled system. Besides, the selection of controller gains is not easy. Mostly, the gain values which are obtained by an analytical method or by simulation do not work well in practice. Moreover, the PI controllers have limited performances, especially with the presence of disturbances, uncertainties, and parameter variation. As a result, the dynamic and stability of the system will be affected [6]. To solve the limitations of the cited methods, robust nonlinear control approaches have been developed to control the induction motor, such as 
the backstepping control, the Sliding Mode Control (SMC), and the Input-Output Feedback Linearization (IOFL) [712]. The IOFL transforms the nonlinear system into a simple equivalent linear one, which can be easily used for the control design [10]. The IOFL utilizes an inverse mathematical transformation to obtain an appropriate control law to control the original nonlinear system. This control strategy has been associated with the SVM-DTC in various research works to improve the AC drive performances [11, 12].

The sliding mode control (SMC) is a powerful control technique which uses fast switching of a control quantity in order to achieve a fast and robust dynamic response [8]. The SMC is suitable for systems with modeling uncertainties and variable parameters, or in the presence of large external disturbances. In addition, the exact knowledge of the system parameters is not required. Despite these advantages, the first-order SMC was quite rarely applied to electric drives control, mainly due to the presence of chattering [13]. Traditional solutions have been developed to reduce the chattering phenomenon, which are

(a) Replacing the discontinuous control function by "saturation" or "sigmoid ones $[14,15]$. This approach guarantees a continuous control and prevents the chattering. However, the main limitation factor of this solution is that the sliding system trajectory does not exactly converge towards the sliding surface, but around its vicinity which drop the system robustness under the disturbances.

(b) Using controllers with dynamical gains. Recently, adaptive sliding mode controllers have been proposed, the interest being the adaptation of the gain magnitude with respect to uncertainty/perturbation effects. Then, a reduced gain induces lower chattering. In [16], an adaptive (first order) sliding mode controller has been proposed and has been evaluated for the control of an electropneumatic actuator. In [17], a robust adaptive sliding mode controller is proposed for Takagi-Sugeno fuzzy systems.

(c) The Fractional-order sliding mode control has been also proposed by several researchers to overcome the classical sliding mode control limitations [18-20]. Compared with traditional sliding mode controller, the fractional order sliding mode controller contains a fractional order term in the sliding surface [18]. The Fractional calculus is a generalization of integration and differentiation to fractional order fundamental operation [19]. Several research works are focused on fractional order proportional-derivative manifold, which has been applied in antilock braking systems [20], power electronics buck converters [21], and position control of PMSM [22]. The uncertainties are not taken into account during the design of the above controller and the chattering will not be considerably prevented. Usually, the control performance and the dynamic systems can be affected by the nonlinearities of the system, the parametric uncertainties, and the external disturbances. The main drawback of this controller is the careful tuning of fractional operator required. Several researchers have used a fuzzy logic system to tune gain of switching control in fractional order sliding mode controller [23-25]. The fractional order sliding mode controller based on neural network technique has been developed in several research work in order to achieve better performance [26-28]. In paper [29], the authors present a fuzzy fractional order sliding mode controller to control nonlinear systems, where the chattering phenomenon is reduced using a sign function and the controller parameters are adjusted with genetic algorithm. Furthermore, the Fractional order sliding mode controller is utilized to control the buck converters [21]. However, the methods to adjust the parameters are not discussed. In paper of [30], the authors present Fractional order sliding mode control based on reaching law approach, but the methods for parameters tuning are not presented. The fuzzy logic control and neural networks associated with fractional order sliding mode controller offer good performances in terms of robustness and chattering reduction. However, the combination between the sliding mode control and the intelligent techniques increases the complexity of the implemented algorithm which requires digitals circuits with higher computation power.

(d) Higher-order SMC was developed in [31, 32]. The high-order-sliding mode control is the generalization of the first order, which is based on the higherorder time derivatives of the sliding surface instead of acting on its first derivative only. The development of higher order SMC requires the availability of the sliding variable derivatives. However, this method increases the information demand for the controller design. The only exception is the second-order supertwisting sliding mode algorithm that requires only the measurement of the sliding variable $S$. This scheme is extremely robust which makes it attractive for drives control [33].

Motivated by the above discussion, the first contribution of this paper consists in implementing a second order SuperTwisting Speed Controller (STSC) for an induction motor. Among the above methods, this controller is chosen thanks to its simplicity of design and low cost implementation. The STSC is implemented on an FPGA Virtex V. However, it offers better performances under load disturbances, parametric uncertainties, less chattering, and low consumption of resources from the FPGA circuit and is more feasible for practical implementation; this makes a difference between the others published works. For more clarification, a combination between an IOFL and an SVM-DTC (SVM-DTC-IOFL) with a Super-Twisting Speed Controller (STSC) to provide a fast dynamic response, robustness control, less chattering, and low torque and flux ripples is developed in this paper. The second contribution is the design and the hardware implementation on the FPGA of these approaches, utilizing the Xilinx System Generator which enable the automatic generation of the VHDL code for FPGA. The experimental 
validation with an FPGA-board of the proposed SVM-DTCIOFL based on Super-Twisting Speed Controller (STSC) is presented in this work, which makes the difference to other works investigated to control the induction motor. The Super Twisting Speed Controller (STSC) is used to control the rotor speed, in order to provide a good dynamic response and improve the control system robustness under the parameters variations and the mechanical load disturbances and uncertainties and without chattering. The Lyapunov stability theory is used to verify the stability of the STSC and IOFL controllers. In addition, in this paper the proposed STSC is compared with an integral sliding mode speed controller and a Proportional Integral speed controller.

Generally, the frequency inverter of AC drive integrates digital circuits like the STM32F3 and STM32F microcontrollers $[34,35]$ and the Digital Signal Processor (DSP) [36, 37]. However, the STM 32 controllers integrate microprocessors which execute the control algorithm sequentially. Accordingly, the algorithm complexity increases the processing time raises, which consequently creates delays in the control loop and causes additional ripples in the torque and the stator current. The DSP controllers are taken into account like a suitable solution in the applications of electrical drives [38] that are based on a high performing processor core and few peripherals to communicate with the external environment. It is in fact noticeable that the processor's sampling frequency is contingent upon a computational burden as a result of serial processing. As a consequence, the latter reduces the performances of the control algorithm and creates delays within the feedback loop. As a matter of fact, the flux ripples, the torque, and the waveforms of the stator current harmonics will go up $[39,40]$ if the sampling time grows. In order to reduce the DSP calculation burden, some researchers have developed a DSP-FPGA combination. This has been done by distributing to the FPGA some algorithm tasks $[41,42]$, hence reducing the ripples and minimizing the sampling period. Nevertheless, it has been an inappropriate solution for commercialization, for the reason that the cost is high and the interfacing circuits are complex. In the objective of overcoming these limitations, the FPGA has been able to be selected as an alternative solution for the controlling of the induction motor within shorter execution time, which might indeed enhance the high-performance applications. In the recent years, the software solutions such as the DSP have been used by several researchers (e.g., dSPACE 1104) in the goal of controlling the electrical motor [39, 41, 42]. The principal limitation factor of such solutions is the dependence of the processing speed on the algorithm complexity through the adoption of a serial processing [43]. In the same vein, some researchers have explored the FPGA use and utility in order to overcome the DSP limitation [38, 44-47]. Thanks to its parallel processing, the FPGA is chosen in this work. As a result, utilizing the FPGA facilitates the implementation of more complex algorithms with a smaller sampling period and a low execution time, which has the possibility of reaching up to $200 \mathrm{KHz}$ [47]. For the hardware implementation on the FPGA, the SVM-DTC-IOFL, with the STSC algorithm, should be programmed with the VHDL or Verilog description language. Nevertheless, programming the VHDL or
Verilog requires a lot of prototyping time which consequently increases the system cost. To overcome this problem, a Xilinx System Generator (XSG) toolbox is proposed in this work to automatically generate the VHDL code and the bitstream file $[48,49]$. The toolbox XSG is developed by Xilinx to be integrated into a Simulink environment and helps the designer rapidly implement control algorithms of the FPGA circuits [50].

In this paper, we propose firstly a combination between SVM-DTC, the IOFL, and the STSC to form a new robust control scheme. In different speed regions and rated load torque, the proposed scheme guarantees an operation with reduced torque ripples, lower chattering amplitude and high robustness against the external disturbances and parameter uncertainties. The second contribution of this paper consists in implementing the proposed scheme on an FPGA. In fact, the FPGA implementation of the control algorithms can efficiently answer current and future challenges of this field. Among them, we can quote the following:

(a) Using the FPGA, the cost of the control system can be reduced for the following reasons: the designer can choose the hardware architecture based only on the specific needs of the control algorithm and the reduction of the time market by using specific and advanced methodologies of implementation. In this work the Xilinx System Generator tool is utilized to implement the proposed control algorithm.

(b) Improvement of the control system performances by reducing the execution time designing dedicated parallel architectures, allowing FPGA-based controllers to reach the level of performance offered by the analog solutions.

In the rest of the paper, this work is organized as follows. In Section 2, the state model of an induction motor and the theory of the IOFL are presented. In Section 3, the PI speed controller, the FOSMSC, and the STSC are developed. In Section 4, the simulation results are presented to test the performances of the suggested control strategy. After that, the experimental implementation on an FPGA Virtex $\mathrm{V}$ is presented in Section 5. Finally, we conclude in Section 6.

\section{DTC of Induction Motor Based on SVM and IOFL}

The conventional DTC strategy produces a torque and a flux with large ripples, which causes an acoustical noise, due to the lack in the control of the switching frequency. The SVM-DTC is proposed to conserve the conventional DTC advantages and to overcome its limitations. The nonlinear IOFL is suggested to provide a perfect decoupled control of the stator flux and the torque.

2.1. Induction Motor Modelling. The squirrel cage induction motor is utilized in several applications, such as belt conveyors and pumps. It is featured by high mechanical robustness and known by good standardization between the manufacturers [51]. The induction motor model is presented 
as follows, which will be used to design the proposed IOFL approach. Several assumptions are present to model the three-phase induction motor: each stator winding is distributed in order to produce a sinusoidal mmf along the air gap. The rotor is a squirrel cage, and the air gap of the machines is considered uniform. The mutual inductances are equal. The saturation of the magnetic circuit, the hysteresis, and eddy current losses are neglected. Indeed, the dynamic behavior of the Induction Motor in the stationary reference $(\alpha, \beta)$ can be described below. The stator voltage vector $\bar{v}_{s}$ in the stationary reference $(\alpha, \beta)$ is expressed by

$$
\begin{aligned}
& v_{s \alpha}=\frac{d \phi_{s \alpha}}{d t}+R_{s} i_{s \alpha} \\
& v_{s \beta}=\frac{d \phi_{s \beta}}{d t}+R_{s} i_{s \beta} \\
& \bar{v}_{s}=\frac{d \bar{\phi}_{s}}{d t}+R_{s} \bar{i}_{s}
\end{aligned}
$$

where $\left(v_{s \alpha}, v_{s \beta}\right),\left(\phi_{s \alpha}, \phi_{s \beta}\right)$, and $\left(i_{s \alpha}, i_{s \beta}\right)$ are the components of the voltage, the stator flux, and stator current, respectively, in the Concordia reference $(\alpha, \beta)$. $R_{s}$ denotes the stator resistance. The time derivative of the rotor flux in the Concordia reference $(\alpha, \beta)$ can be expressed as follows:

$$
\begin{aligned}
& \frac{d \phi_{r \alpha}}{d t}=-R_{r} i_{r \alpha}-\omega_{m} \phi_{r \beta} \\
& \frac{d \phi_{r \beta}}{d t}=-R_{r} i_{r \beta}-\omega_{m} \phi_{r \alpha}
\end{aligned}
$$

where $\left(\phi_{r \alpha}, \phi_{r \beta}\right)$ and $\left(i_{r \alpha}, i_{r \beta}\right)$ are the components of the rotor flux and the rotor current, respectively. $R_{r}$ and $\omega_{m}$ are the rotor resistance and the motor speed, respectively. The stator flux vector $\bar{\phi}_{s}$ and its components can be written as

$$
\begin{aligned}
& \phi_{s \alpha}=L_{s} i_{s \alpha}+M i_{r \alpha} \\
& \phi_{s \beta}=L_{s} i_{s \beta}+M i_{r \beta} \\
& \bar{\phi}_{s}=L_{s} \bar{i}_{s}+M \bar{i}_{r}
\end{aligned}
$$

(i) The stator flux vector $\bar{\phi}_{r}$ and its components can written as

$$
\begin{aligned}
& \phi_{r \alpha}=L_{r} i_{r \alpha}+M i_{s \alpha} \\
& \phi_{r \beta}=L_{r} i_{r \alpha}+M i_{s \beta} \\
& \bar{\phi}_{r}=L_{r} \bar{i}_{r}+M \bar{i}_{s}
\end{aligned}
$$

where $L_{s}, L_{r}$, and $M$ are the stator, rotor, and mutual inductances, respectively. The mechanical motor behavior is described as follows [52]:

$$
J \frac{d \Omega_{m}}{d t}=T_{e m}-T_{l}-f \Omega_{m}
$$

where $T_{e m}, T_{l}, J$ and $f$ are the electromagnetic torque, the load one, rotor inertia, and viscous friction coefficient.
The electromagnetic torque developed by the motor can be estimated as follows [4]:

$$
T_{e m}=\frac{3}{2} N_{p}\left(\phi_{s \alpha} i_{s \beta}-\phi_{s \beta} i_{s \alpha}\right)
$$

with $N_{p}$ denoting the pole pairs.

The time derivative of the stator current and the stator flux components describes the state model of the induction motor, as follows [10]:

$$
\begin{aligned}
\frac{d i_{s \alpha}}{d t}= & -\frac{1}{\sigma}\left(\frac{1}{T_{r}}+\frac{1}{T_{s}}\right) i_{s \alpha}-\omega_{m} i_{s \alpha}+\frac{1}{\sigma L_{s} T_{r}} \phi_{s \alpha} \\
& +\frac{\omega_{m}}{\sigma L_{s}} \phi_{s \beta}+\frac{1}{\sigma L_{s}} v_{s \alpha} \\
\frac{d i_{s \beta}}{d t}= & \omega_{m} i_{s \alpha}-\frac{1}{\sigma}\left(\frac{1}{T_{r}}+\frac{1}{T_{s}}\right) i_{s \beta}-\frac{\omega_{m}}{\sigma L_{s}} \phi_{s \alpha} \\
& +\frac{1}{\sigma L_{s} T_{r}} \phi_{s \beta}+\frac{1}{\sigma L_{s}} v_{s \beta} \\
\frac{d \phi_{s \alpha}}{d t}= & v_{s \alpha}-R_{s} i_{s \alpha} \\
\frac{d \phi_{s \beta}}{d t}= & v_{s \beta}-R_{s} i_{s \beta}
\end{aligned}
$$

Using (7), the state model of the induction motor can be rewritten by

$$
\dot{x}=f(x)+g v_{s \alpha \beta}
$$

with

$$
x=\left[\begin{array}{llll}
i_{s \alpha} & i_{s \beta} & \phi_{s \alpha} & \phi_{s \beta}
\end{array}\right]^{T}
$$

$f(x)$

$=\left[\begin{array}{c}-\frac{1}{\sigma}\left(\frac{1}{T_{r}}+\frac{1}{T_{s}}\right) i_{s \alpha}-\omega_{m} i_{s \alpha}+\frac{1}{\sigma L_{s} T_{r}} \phi_{s \alpha}+\frac{\omega_{m}}{\sigma L_{s}} \phi_{s \beta} \\ \omega_{m} i_{s \alpha}-\frac{1}{\sigma}\left(\frac{1}{T_{r}}+\frac{1}{T_{s}}\right) i_{s \beta}-\frac{\omega_{m}}{\sigma L_{s}} \phi_{s \alpha}+\frac{1}{\sigma L_{s} T_{r}} \phi_{s \beta} \\ -R_{s} i_{s \alpha} \\ -R_{s} i_{s \beta}\end{array}\right]$

$g=\left[\begin{array}{cc}\frac{1}{\sigma L_{s}} & 0 \\ 0 & \frac{1}{\sigma L_{s}} \\ 1 & 0 \\ 0 & 1\end{array}\right]$,

$v_{s \alpha \beta}=\left[\begin{array}{l}v_{s \alpha} \\ v_{s \beta}\end{array}\right]$

where

(i) $\left(T_{r}, T_{s}\right)$ : the rotor and stator time constants.

(ii) $\sigma=1-M_{s r}^{2} / L_{r} L_{s}$ : the Blondel coefficient, where $M_{s r}$ presents the mutual inductance. 


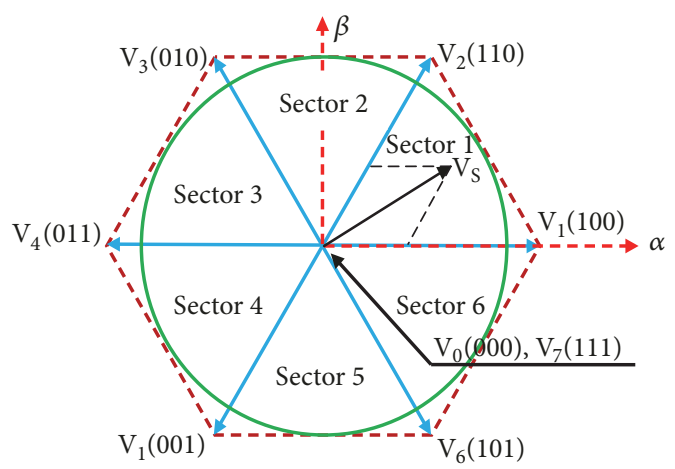

FIGURE 1: Voltage vectors.

2.2. SVM Technique Principle. In the conventional DTC, the torque and the flux ripples are enormously affected by the hysteresis bands. In fact, the large hysteresis band increases the torque ripples and decreases the switching frequency and vice versa. If the hysteresis bandwidth is reduced the switching frequency of the inverter increases, which consequently raises the losses in the inverter [4]. The SVM is a way of reducing the ripples and the current distortions and offering an operation with a constant switching frequency by selecting the appropriate voltage vector for each sampling period [53]. The SVM principle is to modulate the components of the reference voltage vector and generate the corresponding inverter switching states. In the SVM method, the reference voltage vector is calculated by the projection of the two nearest adjacent vectors in each sector $\mathrm{N}_{\mathrm{i}}:(i-1)(\pi / 3)<\mathrm{S}_{\mathrm{i}} \leq$ $i(\pi / 3)$, as shown in Figure 1.

The commutation times can be obtained with the voltage vector components and the null vector must be applied in the remainder of the time period to maintain the switching frequency constant [54]. In sector 1, with a simple projection, the commutation times and voltage vectors are presented in

$$
\begin{aligned}
\vec{V}_{S} & =V_{s \alpha}^{*}+j V_{s \beta}^{*}=\frac{T_{1}}{T_{m}} \vec{V}_{1}+\frac{T_{2}}{T_{m}} \vec{V}_{2} \\
\vec{V}_{1} & =\sqrt{\frac{2}{3}} U_{d c}(\cos (0)+j \sin (0))=\sqrt{\frac{2}{3}} U_{d c} \\
\vec{V}_{2} & =\sqrt{\frac{2}{3}} U_{d c}\left(\cos \left(\frac{\pi}{3}\right)+j \sin \left(\frac{\pi}{3}\right)\right) \\
T_{m} & =T_{1}+T_{2}+T_{0} \\
T_{1} & =\left(\sqrt{\frac{3}{2}} V_{S \alpha}-\frac{1}{\sqrt{2}} V_{S \beta}\right) \frac{T_{m}}{U_{d c}} \\
T_{2} & =\sqrt{2} V_{S \alpha} \frac{T_{m o d}}{U_{d c}}
\end{aligned}
$$

where

(i) $\left(v_{s \alpha}^{*}, v_{s \beta}^{*}\right)$ : the components of the reference voltage vector,

(ii) $\mathrm{T}_{1}, \mathrm{~T}_{2}$ : the commutation time, (iii) $\mathrm{T}_{\mathrm{m}}$ : the sampling time,

(iv) $U_{d c}$ : the $D C$ voltage.

2.3. IOFL Control Design. The Feedback Linearization (FL) technique allows the user to utilize the linear control approach with nonlinear systems such as the IM. The FL technique transforms the model of a nonlinear system into a linear equivalent one, so that the linear control approach can be utilized. In order to improve the power efficiency and provide a good dynamic control of the torque of the motor, the proposed outputs of the system are the stator flux norm and the electromagnetic torque. Hence, based on the input output feedback linearization principle, the output variables are considered as

$$
\begin{aligned}
& h_{1}(x)=T_{e m}=\frac{3}{2} N_{p}\left(i_{s \beta} \phi_{s \alpha}-i_{s \alpha} \phi_{s \beta}\right) \\
& h_{2}(x)=\left|\phi_{s}\right|^{2}=\phi_{s \alpha}^{2}+\phi_{s \beta}^{2}
\end{aligned}
$$

where $T_{e m}$ is the estimated electromagnetic torque and $\left|\phi_{s}\right|$ is the norm of the stator flux. Assuming the controller objectives $\mathrm{y}_{1}$ and $\mathrm{y}_{2}$, we get

$$
\begin{aligned}
& y_{1}=h_{1}(x) \\
& y_{2}=h_{2}(x)
\end{aligned}
$$

with $T_{e m}^{*}$ and $\left|\phi_{s}^{*}\right|$ being the torque and flux references, respectively. Utilizing the presented equations, the time derivative of the controller objectives presented by (14) can be written a

$$
\left[\begin{array}{c}
\dot{y}_{1} \\
\dot{y}_{2}
\end{array}\right]=\left[\begin{array}{l}
g_{1}(x) \\
g_{2}(x)
\end{array}\right]+G(x)\left[\begin{array}{c}
v_{s \alpha} \\
v_{s \beta}
\end{array}\right]
$$

The expressions of $g_{1}(x), g_{2}(x)$ and $G(x)$ can be obtained by the combination between the time derivatives of (14) and (7). After development and simplification, the obtained expressions of $g_{1}(x)$ and $g_{2}(x)$ are given by

$$
\begin{aligned}
g_{1}(x) & =\frac{3}{2} N_{p}\left[-\frac{1}{\sigma}\left(\frac{1}{T_{r}}+\frac{1}{T_{s}}\right) \phi_{s \alpha} i_{s \alpha}+\omega_{m} \phi_{s \alpha} i_{s \alpha}\right. \\
- & \frac{\omega_{m}}{\sigma L_{s}} \phi_{s \alpha}^{2}+\frac{1}{\sigma}\left(\frac{1}{T_{r}}+\frac{1}{T_{s}}\right) \phi_{s \beta} i_{s \alpha}+\omega_{m} \phi_{s \beta} i_{s \beta} \\
- & \left.\frac{\omega_{m}}{\sigma L_{s}} \phi_{s \beta}^{2}\right] \\
g_{2}(x) & =-2 R_{s}\left(\phi_{s \alpha} i_{s \alpha}+\phi_{s \beta} i_{s \beta}\right)
\end{aligned}
$$

The matrix $\mathrm{G}(\mathrm{x})$ presented in (15) is given as follows:

$G(x)$

$$
=\left[\begin{array}{cc}
\frac{3}{2} N_{p}\left(i_{s \beta}-\frac{1}{\sigma L_{s}} \phi_{s \beta}\right) & \frac{3}{2} N_{p}\left(\frac{1}{\sigma L_{s}} \phi_{s \alpha}-i_{s \alpha}\right) \\
2 \phi_{s \alpha} & 2 \phi_{s \beta}
\end{array}\right]
$$




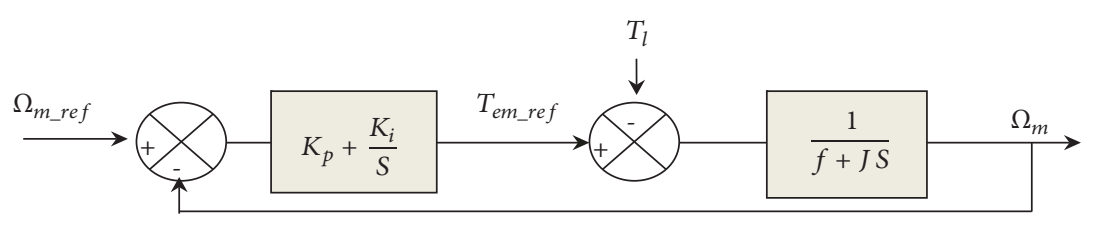

FiguRE 2: Block diagram of the closed-loop PI speed controller.

Utilizing the induction motor model, the relation between the rotor and the stator fluxes is given below:

$$
\begin{aligned}
& \phi_{r \alpha}=\frac{\sigma L_{s} L_{r}}{M_{s r}}\left(\frac{1}{\sigma L_{s}} \phi_{s \alpha}-i_{s \alpha}\right) \\
& \phi_{r \beta}=\frac{\sigma L_{s} L_{r}}{M_{s r}}\left(\frac{1}{\sigma L_{s}} \phi_{s \beta}-i_{s \beta}\right)
\end{aligned}
$$

Substituting (18) into (17), the matrix $\mathrm{G}(\mathrm{x})$ can be rewritten as follows:

$$
G(x)=\left[\begin{array}{cc}
-\frac{3 M_{s r}}{2 \sigma L_{s} L_{r}} N_{p} \phi_{r \beta} & \frac{3 M_{s r}}{2 \sigma L_{s} L_{r}} N_{p} \phi_{r \alpha} \\
2 \phi_{s \alpha} & 2 \phi_{s \beta}
\end{array}\right]
$$

In order to determine the expression of the control inputs $v_{s \alpha}$ and $v_{s \beta}$, the matrix $\mathrm{G}(\mathrm{x})$ must be reversible. The invertibility of $\mathrm{G}(\mathrm{x})$ can be verified by its determinant which is developed in

$$
\operatorname{det}(G)=-\frac{3 M_{s r}}{\sigma L_{s} L_{r}} N_{p}\left(\phi_{r \alpha} \phi_{s \alpha}+\phi_{r \beta} \phi_{s \beta}\right)
$$

Referring to (20), it can be seen that the matrix $G(x)$ is reversible, because the product of the rotor flux and the stator flux cannot be equal to zero [55]; the inverse of $\mathrm{G}(\mathrm{x})$ is written $\mathrm{G}^{-1}(\mathrm{x})$, as given by (14).

$$
\begin{aligned}
G^{-1}(x)= & \frac{-\sigma L_{s} L_{r}}{3 M_{s r} N_{p}\left(\phi_{r \alpha} \phi_{s \alpha}+\phi_{r \beta} \phi_{s \beta}\right)} \\
& \cdot\left[\begin{array}{cc}
2 \phi_{s \beta} & -\frac{3 M_{s r}}{2 \sigma L_{s} L_{r}} N_{p} \phi_{r \alpha} \\
-2 \phi_{s \alpha} & -\frac{3 M_{s r}}{2 \sigma L_{s} L_{r}} N_{p} \phi_{r \beta}
\end{array}\right]
\end{aligned}
$$

Based on the IOFL technique, the control inputs can be expressed as follows [52]:

$$
\left[\begin{array}{c}
v_{s \alpha} \\
v_{s \beta}
\end{array}\right]=G^{-1}(x)\left[\begin{array}{l}
-g_{1}(x)+v_{1} \\
-g_{2}(x)+v_{2}
\end{array}\right]
$$

where $v_{1}$ and $v_{2}$ are assumed to be two auxiliary control inputs. The combination between (15) and (22) gives the system outputs dynamic, which is

$$
\begin{aligned}
& \dot{y}_{1}=v_{1} \\
& \dot{y}_{2}=v_{2}
\end{aligned}
$$

As shown in [56], to ensure a good tracking of torque and the square of the stator flux references $T_{e m}^{*}$ and $\left|\phi_{s}^{*}\right|$, respectively, the internal input signals can be expressed as

$$
\begin{aligned}
& v_{1}=-k_{1}\left(T_{e m}-T_{e m}^{*}\right)+\dot{T}_{e m}^{*} \\
& v_{2}=-k_{2}\left(\left|\phi_{s}\right|^{2}-\left|\phi_{s}^{*}\right|^{2}\right)+\left|\dot{\phi}_{s}^{*}\right|^{2}
\end{aligned}
$$

with $\mathrm{k}_{1}$ and $\mathrm{k}_{2}$ being positive constants. The combination between (14), (23), and (24), the state errors dynamics $e_{1}=$ $T_{e m}-T_{e m}^{*}$ and $e_{2}=\left|\phi_{s}\right|^{2}-\left|\phi_{s}^{*}\right|^{2}$ can be defined as

$$
\begin{aligned}
& \frac{d e_{1}}{d t}=-k_{1} e_{1} \\
& \frac{d e_{2}}{d t}=-k_{2} e_{2}
\end{aligned}
$$

The SVM-DTC-IOFL performance depends strongly on the suitable choice of the parameters $k_{1}$ and $k_{2}$, in order to make the errors $e_{1}$ and $e_{2}$ converge exponentially to zero. In fact, the small values of these parameters cause a poor robustness and a slow convergence, while the great values can lead to the instability of the system. Consequently, the best choice of these parameters is seriously effective on the performance of the control strategy [11]. The FL control law is used in order to satisfy the stability condition defined by the Lyapunov approach. To study the stability of the control law, the Lyapunov function is given as

$$
V(e)=\frac{1}{2} e^{T} e
$$

The time derivative of (26) is given as follows:

$$
\begin{aligned}
\dot{V} & =e^{T} \dot{e}=\left[\begin{array}{ll}
e_{1} & e_{2}
\end{array}\right]\left[\begin{array}{cc}
-k_{1} & 0 \\
0 & -k_{2}
\end{array}\right]\left[\begin{array}{l}
e_{1} \\
e_{2}
\end{array}\right]=-k_{1} e_{1}^{2}-k_{2} e_{2}^{2} \\
& <0
\end{aligned}
$$

The derivative of $\mathrm{V}$ is negative and equilibrium point is globally and exponentially stable.

\section{Synthesis of Speed Controllers}

3.1. PI Speed Controller. The block diagram of the closed-loop speed controller is presented in Figure 2 [59]. The speed loop is realized by a PI controller. The integral and proportional coefficients of this controller are noted $\mathrm{k}_{\mathrm{p}}$ and $\mathrm{k}_{\mathrm{i}}$, respectively.

In Figure 2, the parameters $\mathrm{J}$ and $\mathrm{f}$ denote the inertia moment and the Coefficient of friction, respectively. $\Omega_{m}$ 
and $\Omega_{m_{-} \text {ref }}$ are the actual and the reference rotor speed, respectively. $T_{l}$ and $T_{\text {em_ref }}$ are the load and the reference torque, respectively.

The selection of the parameters of the speed controller is done in order to obtain the desired performances for the closed-loop system by imposing the damping ratio $\xi$ and the natural frequency $\omega_{0}$.

Referring to Figure 2, the closed loop transfer function of $\mathrm{H}_{\mathrm{cl}}$ (s) can be expressed as follows:

$$
H_{c l}(s)=\frac{\left(K_{p} / K_{i}\right) s+1}{\left(J / K_{i}\right) s^{2}+\left(\left(K_{p}+f\right) / K_{i}\right) s+1}
$$

After identifying the denominator in its canonical form given in (29), the Proportional and the Integral coefficients of the speed controller can be obtained by solving (30).

$$
\begin{aligned}
H_{c l}(s) & =\frac{1}{\left(1 / \omega_{0}^{2}\right) s+\left(2 \xi / \omega_{0}\right) s+1} \\
\frac{J}{K_{i}} & =\frac{1}{\omega_{0}^{2}} \\
\frac{K_{p}+f}{K_{i}} & =\frac{2 \xi}{\omega_{0}}
\end{aligned}
$$

In order to obtain a response without overshoot, the damping coefficient is fixed at $\xi=1$ which correspond the following relation $\omega_{0} t_{\text {rep }}=4,75$ as given in Table $10 . t_{\text {rep }}$ presents the time of the speed response. The parameters of speed controller are expressed as follows:

$$
\begin{aligned}
K_{i} & =J \omega_{0}^{2} \\
K_{p} & =\frac{2 \xi}{\omega_{0}} K_{i}-f
\end{aligned}
$$

3.2. Synthesis of Integral Sliding Mode Speed Controller. The integral sliding mode speed controller is used to generate the torque reference $T_{e m}^{*}$. The mechanical equation of the motor is written as

$$
\frac{d \Omega_{m}(t)}{d t}=\frac{1}{J}\left(T_{e m}-T_{l}-f \Omega_{m}\right)
$$

where $\Omega_{\mathrm{m}}$ is the rotor speed. $\mathrm{T}_{\mathrm{em}}$ and $\mathrm{T}_{1}$ are, respectively, the electromagnetic torque and the load torque, $\mathrm{f}$ presents the coefficient of friction, and J is the inertia constant. Equation (32) can be rewritten as follows:

$$
\begin{aligned}
\dot{\Omega}_{m} & =\frac{1}{J}\left(T_{e m}-T_{l}\right)+\left(-\frac{f}{J}\right) \Omega_{m} \\
& =\alpha \Omega_{m}+\beta\left(T_{e m}-T_{l}\right) \\
& =\left(\alpha_{0}+\Delta \alpha\right) \Omega_{m}+\left(\beta_{0}+\Delta \beta\right)\left(T_{e m}-T_{l}\right) \\
& =\alpha_{0} \Omega_{m}+\beta_{0}(u(t)+g)
\end{aligned}
$$

with

$$
\begin{aligned}
\alpha & =-\frac{f}{J}=\alpha_{0}+\Delta \alpha \\
\beta & =\frac{1}{J}=\beta_{0}+\Delta \beta \\
u(t) & =T_{e m} \\
g & =\frac{1}{\beta_{0}}\left(\Delta \alpha \Omega_{m}+\Delta \beta u(t)-\beta T_{l}\right)
\end{aligned}
$$

where " $\Delta$ " presents the uncertainty, the index "o" indicates the nominal value, and " $g$ " represents the lumped uncertainties. To determine the equivalent control law, the sliding surface can be defined as [60]

$$
S_{\Omega}=e(t)+\lambda \int_{0}^{t} e(\tau) d \tau, \quad \lambda>0 .
$$

where $e(t)=\Omega_{m-r e f}-\Omega_{m}$ presents the speed error. The control law can be defined by the following expression [61]:

$$
u(t)=u_{e q}(t)+u_{n}(t)
$$

where the equivalent control law $\mathrm{u}_{\mathrm{eq}}$ is utilized to control the system behavior and the term $\mathrm{u}_{\mathrm{n}}$ is a relay control function used to reject the disturbances and the parameter variations. The discontinuous term $u_{n}$ can be expressed as [61]

$$
u_{n}=K \operatorname{sign}\left(S_{\Omega}\right)
$$

Due to its discontinuous nature, this term generates a chattering phenomenon that can be reduced utilizing a smooth control function [61]. The condition $\dot{S}_{\Omega}=0$ is used for the equivalent control concept. Thus the following is obtained:

$$
\begin{aligned}
\dot{S}_{\Omega}= & \dot{e}(t)+\lambda e(t)=\dot{\Omega}_{m-r e f}-\dot{\Omega}_{m}+\lambda e(t) \\
= & \dot{\Omega}_{m-r e f}-\alpha_{0} \Omega_{m}-\beta_{0}\left(u_{e q}(t)+u_{n}(t)+g\right) \\
& +\lambda e(t) \\
= & \left(\dot{\Omega}_{m-r e f}-\alpha_{0} \Omega_{m}-\beta_{0} u_{e q}(t)+\lambda e(t)\right) \\
& -\beta_{0}\left(g+u_{n}(t)\right)
\end{aligned}
$$

To satisfy the equivalent control concept $\dot{S}_{\Omega}=0$, we can get

$$
u_{e q}(t)=\frac{1}{\beta_{0}}\left(\dot{\Omega}_{m-r e f}-\alpha_{0} \Omega_{m}+\lambda e(t)\right)
$$

Hence, the sliding mode speed controller is defined as follows:

$$
\begin{aligned}
T_{\text {em-ref }}= & u(t) \\
= & \frac{1}{\beta_{0}}\left(\dot{\Omega}_{m-r e f}-\alpha_{0} \Omega_{m}+\lambda e(t)\right) \\
& +K \operatorname{sign}\left(S_{\Omega}\right)
\end{aligned}
$$


To verify the stability of the system, the Lyapunov function can be utilized, which is represented as follows [62]:

$$
V=\frac{1}{2} S_{\Omega}^{2}
$$

If the time derivative of $\mathrm{V}$ is negative definite, the existence and reachability conditions of a sliding mode are verified. Referring to the Lyapunov function given by (41), the time derivative of $\mathrm{V}$ can be expressed as [63]

$$
\dot{V}=S_{\Omega} \dot{S}_{\Omega}<0
$$

Consequently, the reachability condition of the sliding mode speed controller is verified as follows. The combination between (38) and (41) gives

$$
\begin{aligned}
\dot{V} & =S_{\Omega}\left(\left(\dot{\Omega}_{m-r e f}-\alpha_{0} \Omega_{m}-\beta_{0} u_{e q}(t)+\lambda e(t)\right)\right. \\
& \left.-\beta_{0}\left(g+u_{n}(t)\right)\right)<0
\end{aligned}
$$

Replacing (37) and (38) into (42), we can get

$$
\begin{aligned}
\dot{V} & =S_{\Omega}\left((\underbrace{\dot{\Omega}_{m-r e f}-\alpha_{0} \Omega_{m}-\beta_{0}\left(\left(1 / \beta_{0}\right)\left(\dot{\Omega}_{m-r e f}-\alpha_{0} \Omega_{m}+\lambda e(t)\right)\right)+\lambda e(t)}_{=0})-\beta_{0}\left(g+u_{n}(t)\right)\right) \\
& =-S_{\Omega} \beta_{0}\left(g+u_{n}(t)\right) \\
& =-S_{\Omega} \beta_{0}\left(g+K \operatorname{sign}\left(S_{\Omega}\right)\right)<0
\end{aligned}
$$

To satisfy the reaching condition $S_{\Omega} \dot{S}_{\Omega}<0$ and ensure the speed controller stability, we can get the inequality $g<K$.

Generally, the first-order sliding mode controller based drive system has many attractive features such as the following: (a) it is robust to parameter variations and model uncertainties and insensitive to external load disturbance; (b) it offers a fast dynamic response, and stable control system; and (c) it requires an easy hardware/software implementation. However, in the conventional sliding mode control, the robustness of the system against parameters variation and external disturbances is achieved in the sliding phase. During the reaching phase, the robustness is not guaranteed. To overcome this problem, the Integral sliding mode control has been proposed in [64] which eliminates the reaching phase; thus, sliding phase will be enforced through the entire system response [65]. The main Integral sliding mode control drawbacks is the difficulty of parameter tuning of its gain, which is required to ensure a compromise between disturbance rejection property of the controller and the chattering phenomenon. As shown in (40), the integral sliding mode control law contains a discontinue term. However, due to discontinuous nature, it has some limitations in electrical drives and shows high-frequency oscillations as chattering characteristics. The chattering makes various undesirable effects such as current harmonics and torque pulsation $[17,66]$. To reduce the chattering, a super-twisting speed controller is proposed and developed in Section 3.3. However, the super-twisting sliding mode controller guarantees the first-order sliding mode controller advantages and generates a continuous control signal which consequently reduces the chattering phenomenon [67].

3.3. Synthesis of Super-Twisting Rotor Speed Controller. The super-twisting algorithm is designed to perform a continuous control with a two-order sliding mode control utilizing only the information about the sliding surface (S), whose of the $\dot{S}$ derivate is not necessary. The super-twisting (ST) control law $\mathrm{u}(\mathrm{t})$ is defined by two parts $\mathrm{u}_{1}$ and $\mathrm{u}_{2}$. The ST control law is presented by $[68,69]$

$$
u_{S T}=u_{1}(t)+u_{2}(t)
$$

with:

$$
\begin{aligned}
& \dot{u}_{1}=-\delta_{\Omega} \operatorname{sign}\left(S_{\Omega}\right) \\
& u_{2}=-\mu_{\Omega}\left|S_{\Omega}\right|^{\eta} \operatorname{sign}\left(S_{\Omega}\right)+u_{1}
\end{aligned}
$$

where $S_{\Omega}$ is the sliding surface, which is given as follows:

$$
S_{\Omega}=\Omega_{m}^{*}-\Omega_{m}
$$

$\delta_{\Omega}$ and $\mu_{\Omega}$ are positive constants, which are utilized to synthesize a robust ST controller. The parameter $\eta$ presents the degree of nonlinearity, which is generally defined as " $0<$ $\eta \leq 0.5$ ". This parameter is mostly equal to $0.5[70,71]$. The sufficient conditions to offer a finite time convergence are given as follows [71, 72]:

$$
\begin{aligned}
& \delta_{\Omega}>\frac{\Phi}{\Gamma_{m}} \\
& \mu_{\Omega}^{2} \geq \frac{4 \Phi}{\Gamma_{m}^{2}} \frac{\Gamma_{M}\left(\delta_{\Omega}+\Phi\right)}{\Gamma_{m}\left(\delta_{\Omega}-\Phi\right)}
\end{aligned}
$$

where $\delta_{\Omega}, \mu_{\Omega}, \Phi$, and $\Gamma_{m}$ are chosen as positive constants [73], $\Phi$ is considered as the positive bound of the function $\phi$, and $\Gamma_{\mathrm{m}}$ and $\Gamma_{\mathrm{M}}$ are considered as the bounds of the function $\gamma$ at the second derivative of the sliding surface [74], with

$$
\ddot{S}_{\Omega}=\phi(x, t)+\gamma(x, t) \dot{u}
$$

To guarantee the convergence of the sliding surface to zero in the presence of disturbances and uncertainties, 


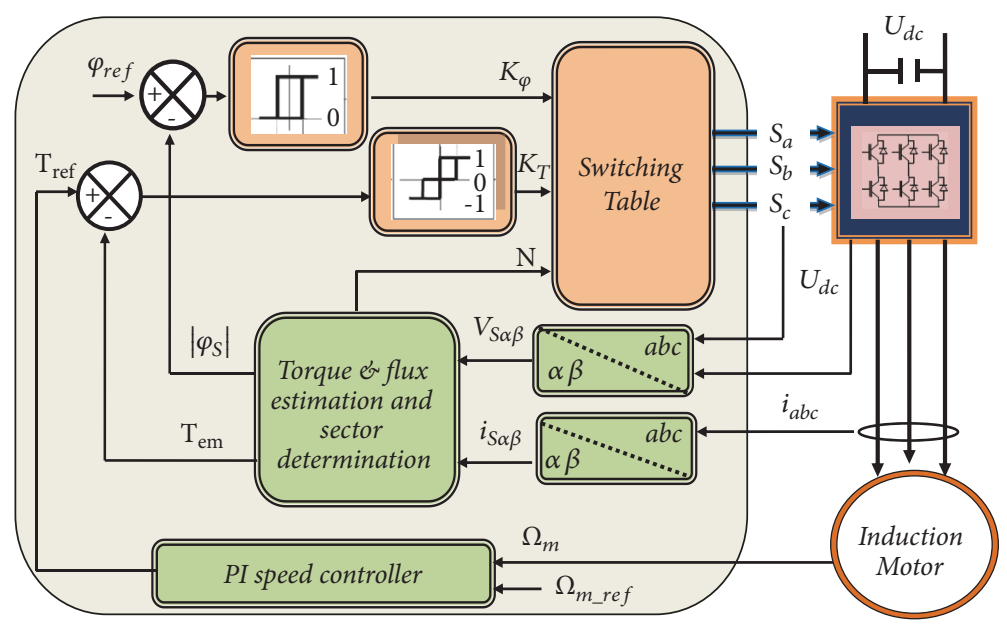

FIGURE 3: Global diagram of conventional DTC.

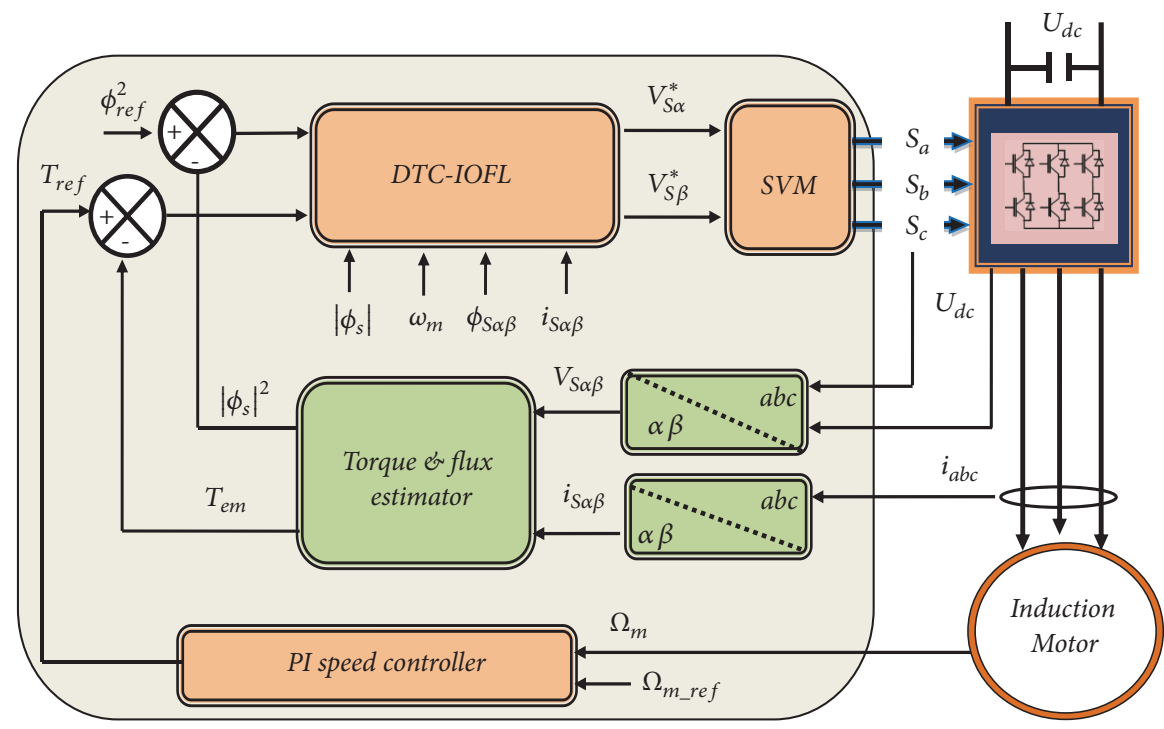

FIgURE 4: Global diagram of SVM-DTC-IOFL based on PI speed controller.

the functions $\phi(x, t)$ and $\gamma(x, t)$ must verify the following conditions: $\Phi \geq|\phi|$ and $\Gamma_{M} \geq \gamma \geq \Gamma_{m}>0$. The reference of the torque generated by the sliding mode controller can be expressed as follows:

$$
T_{\text {em_ref }}=T_{\text {em_eq }}+u_{S T}
$$

The global diagrams of the conventional DTC, the proposed SVM-DTC-IOFL based on PI controller, the SVMDTC-IOFL based on FOSMSC and the proposed SVM-DTCIOFL based on STSC controller are shown in Figures 3, 4, 5, and 6 , respectively.

\section{Simulation Results}

The developed control algorithms are verified by digital simulation utilizing the XSG under a Matlab/Simulink environment. The IM parameters and characteristics are presented in the Appendix. In this section, the simulation results of the conventional DTC, the SVM-DTC-IOFL based on PI speed controller and the SVM-DTC-IOFL based on STSC will be presented and analyzed. To get these results, the diagrams of the three approaches are realized with the XSG toolbox. Xilinx created the XSG toolbox in the aim of being integrated within Simulink. This toolbox comprises many block sets utilized for the system design and to test as well the functionality of the hardware system by simulation. When the design is achieved, giving the desired results of simulation the XSG offer the possibility of automatically generating the VHDL code. The generated VHDL code can be then synthesized and implemented on the FPGA. Figure 7 shows the design flow utilizing the XSG. The architecture of the SVM-DTC-IOFL based on STSC from the XSG is presented by Figure 8 .

In this study, a 16-bits fixed-point format is chosen. The sizes of decimal and entire parts are given in Table 1. 


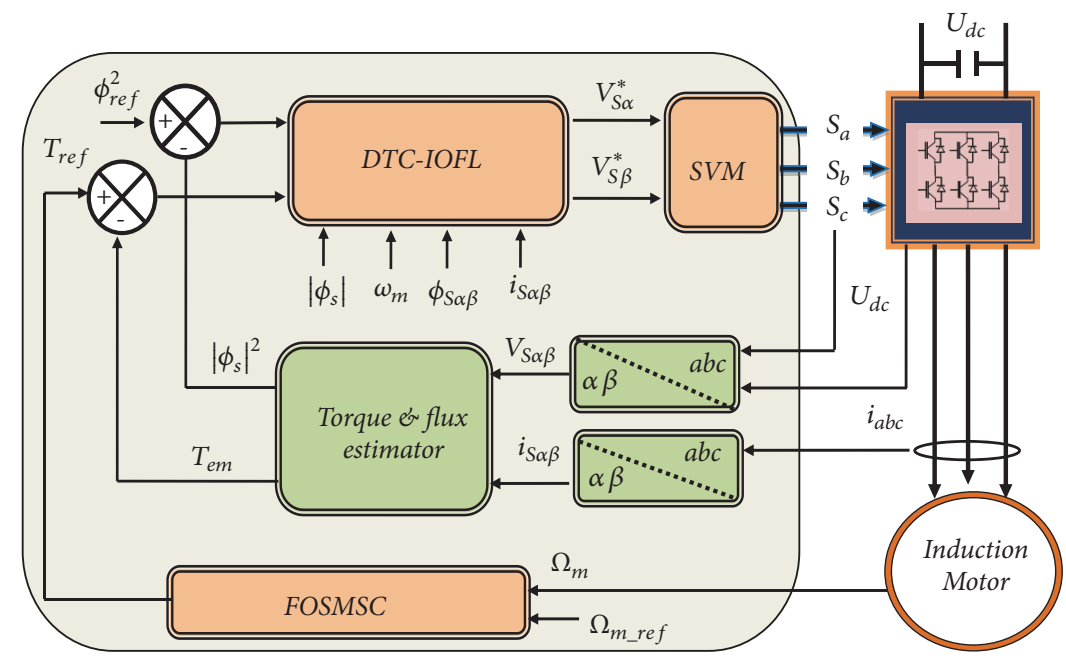

FIGURE 5: Global diagram of SVM-DTC-IOFL based on FOSMSC.

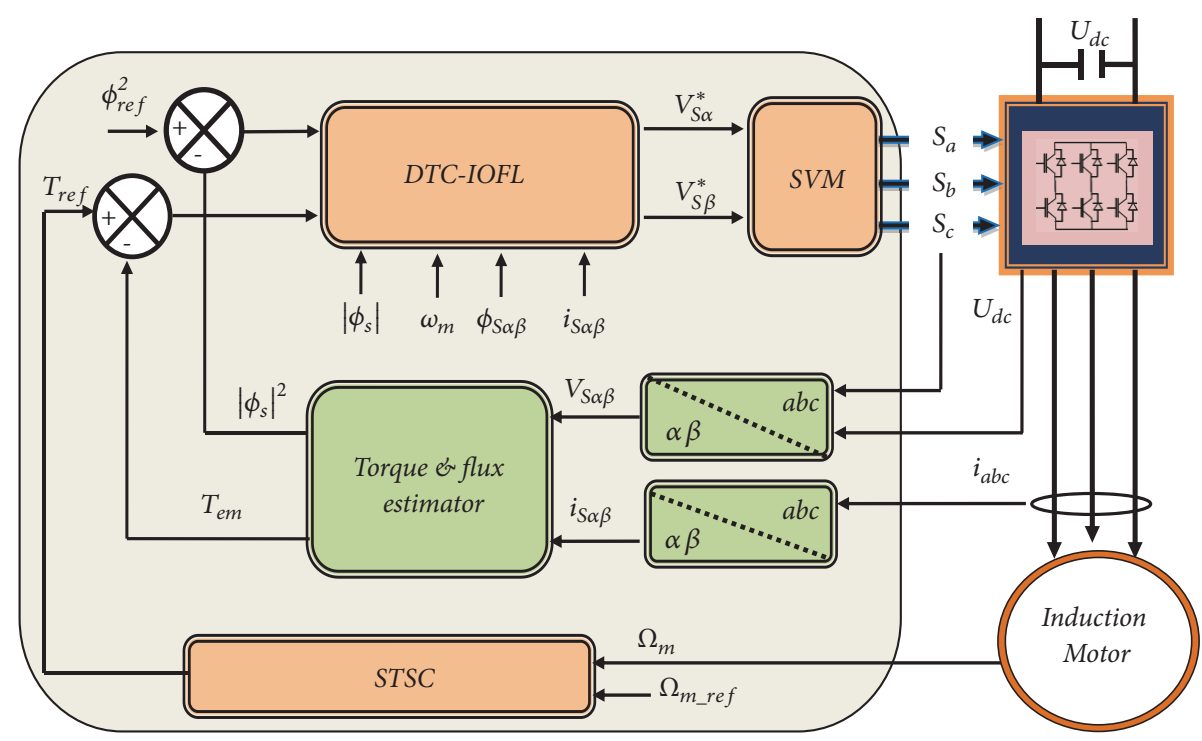

FIGURE 6: Global diagram of SVM-DTC-IOFL based on STSC.

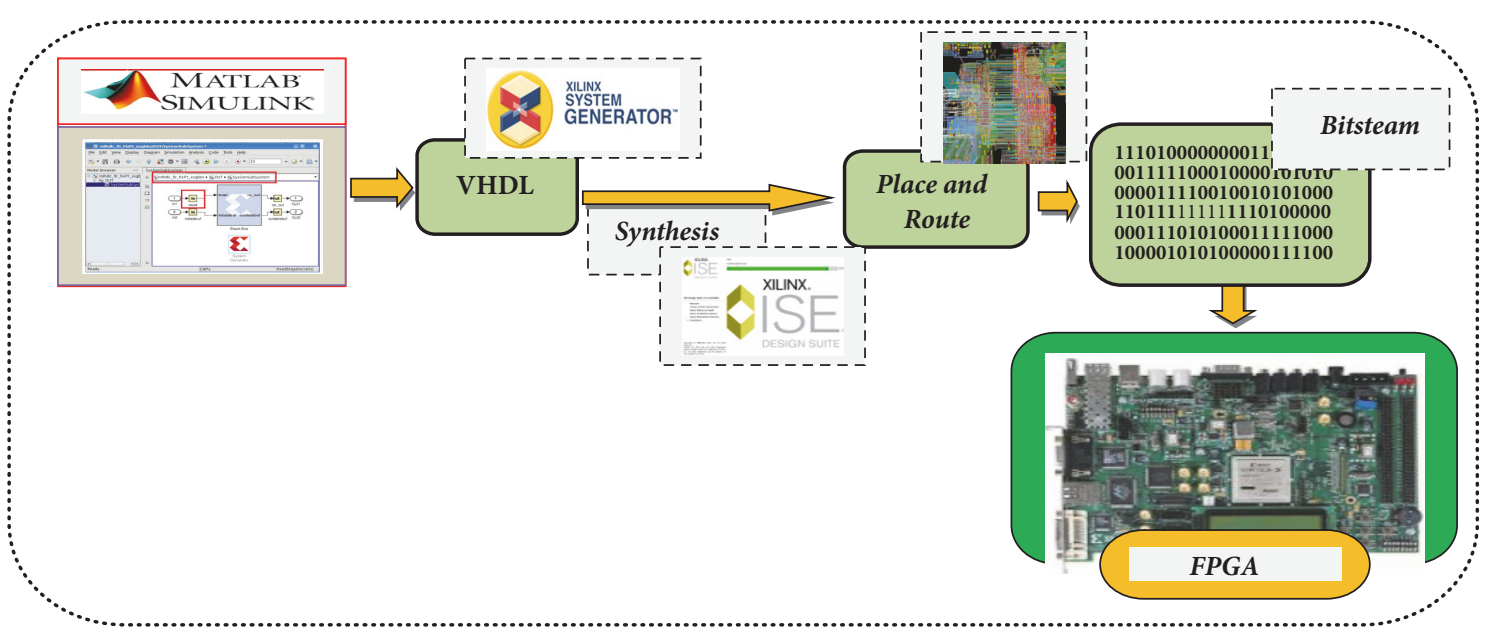

FIgURE 7: XSG design flow. 


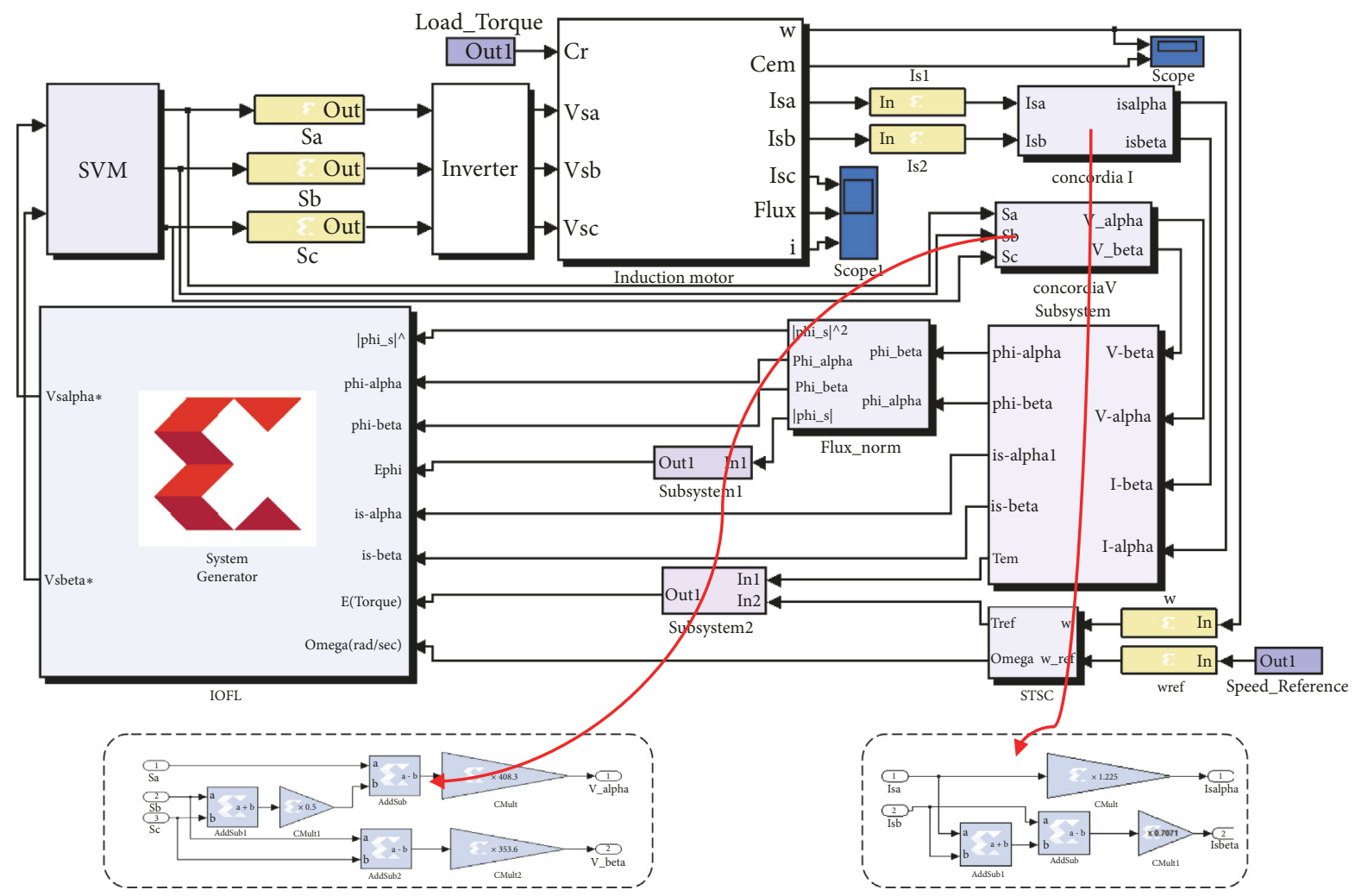

FIGURE 8: Full architecture of SVM-DTC-IOFL based on STSC from XSG.

TABLE 1: 16-bit fixed point data format.

\begin{tabular}{lcc}
\hline Sign & Fixed entire part & Fixed decimal part \\
\hline$[1$ bit $]$ & {$[5$ bits $]$} & {$[10$ bits $]$} \\
\hline
\end{tabular}

4.1. Comparative Study between Four Approaches at Rated Speed $(150 \mathrm{Rad} / \mathrm{Sec})$. The objective of this study is to test the performances of the proposed SVM-DTC-IOFL based on PI speed controller, the SVM-DTC-IOFL based on FOSMSC, and the SVM-DTC-IOFL based on STSC in terms of ripples and speed deviation when the load torque is applied. The reference speed is equal to $150 \mathrm{rad} / \mathrm{sec}$. The rated load torque equal to $10 \mathrm{Nm}$ is applied at $\mathrm{t}=0.5 \mathrm{sec}$. The parameters of the Induction motor are given by the Table 8 which is presented in the Appendix. The parameters of the IOFL, the STSC, the FOSMSC, and the PI speed controllers are presented in the Appendix (Table 9).

Figures 9-13 present the rotor speed evolution, the electromagnetic torque response, the norm of the stator flux, the phase stator current, and the stator flux trajectory, respectively. Firstly, Figure 9 presents a comparative study in terms of speed response with $150 \mathrm{rad} / \mathrm{sec}$ as a reference speed. An external disturbance as a load torque is applied at $\mathrm{t}=0.5 \mathrm{sec}$. Referring to this figure, it is shown that the three techniques offer a good dynamic response when starting up. It can be noticed that the SVM-DTC-IOFL based on STSC has the faster speed response and the least deviation under a load torque application, as depicted in
Figure 9(d). In fact, more details are presented in Table 2. Figures $10(\mathrm{a}), 10(\mathrm{~b}), 10(\mathrm{c})$, and $10(\mathrm{~d})$ illustrates the torque responses produced by the four control techniques with load torque application at $\mathrm{t}=0.5 \mathrm{sec}$. It can be seen that the torque ripples are reduced in the SVM-DTC-IOFL based on PI controller, the SVM-DTC-IOFL based on FOSMC and the SVM-DTC-IOFL based on STSC compared with the conventional DTC, thanks to the SVM technique. The torque ripples are considerably reduced with the SVM-DTCIOFL based on STSC as indicated in Figure 10(d). However, relative to SVM-DTC-IOFL based on PI controller, the SVMDTC-IOFL based on FOSMC presents more torque ripples, due to the chattering phenomenon. As shown in Figures 11 and 12, the stator flux ripples are reduced with a good tracking in the proposed approach. It can be seen that the SVM-DTC-IOFL based on STSC has a low flux ripples relative to the SVM-DTC-IOFL based on FOSMC due to the chattering phenomenon. After that, in Figure 13, the stator current evolution is presented. It can be noticed that the stator current has a good sinusoid waveform in the SVM-DTCIOFL based on PI and SVM-DTC-IOFL based on STSC, but in the conventional DTC the stator current has important harmonics. Figure 14 illustrates the evolution of the rotor speed and the electromagnetic torque with different speed references and at a locked rotor $[100 \mathrm{rad} / \mathrm{sec} \longrightarrow 150 \mathrm{rad} / \mathrm{sec} \longrightarrow$ $0 \mathrm{rad} / \mathrm{sec} \longrightarrow-150 \mathrm{rad} / \mathrm{sec}]$ under a rated load torque, obtained using the SVM-DTC-IOFL based on STSC. It can be noticed that the STSC offers a fast dynamic response and a good reference tracking. The load influence is insignificant (as 


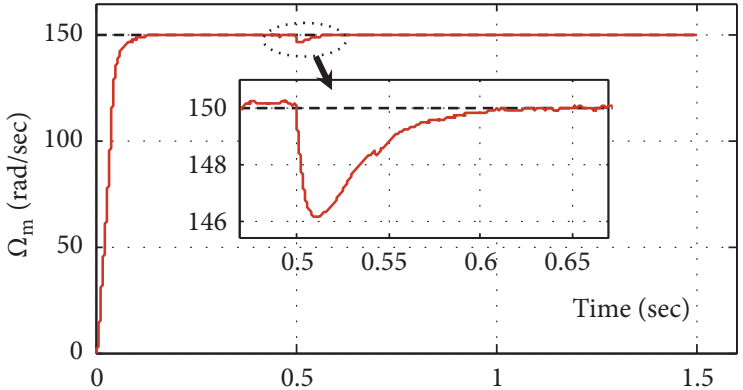

(a)

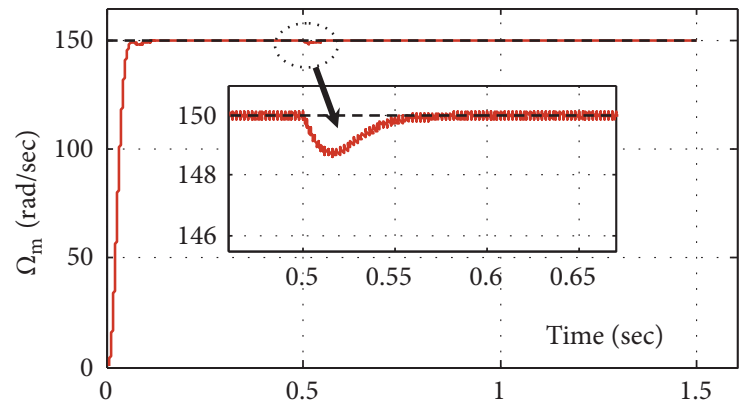

(c)

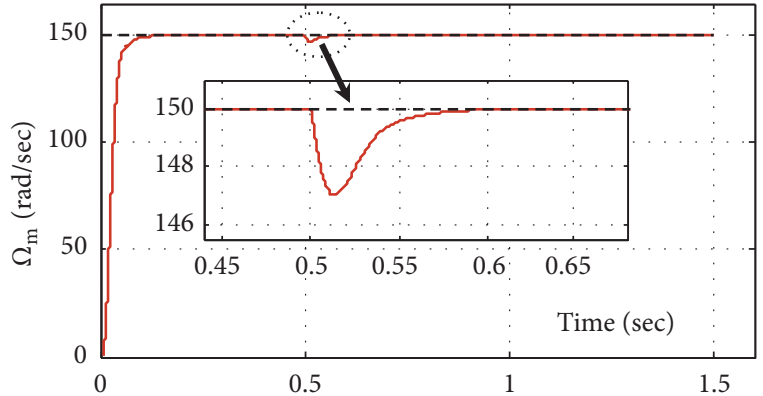

(b)

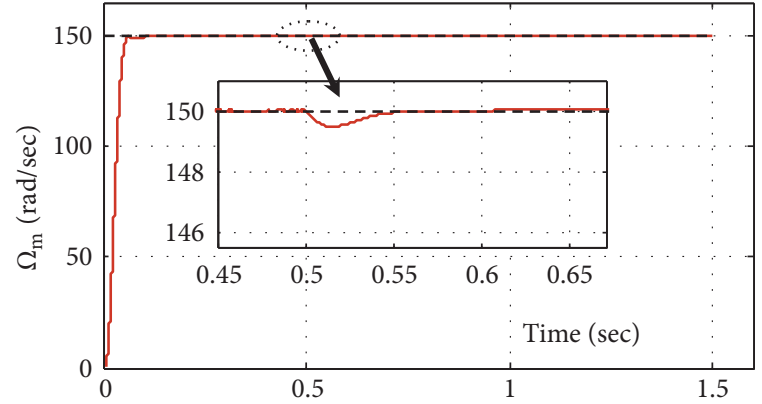

(d)

FIGURE 9: Speed response for (a) conventional DTC, (b) SVM-DTC-IOFL based on PI controller, (c) SVM-DTC-IOFL based on FOSMSC, and (d) SVM-DTC-IOFL based on STSC.

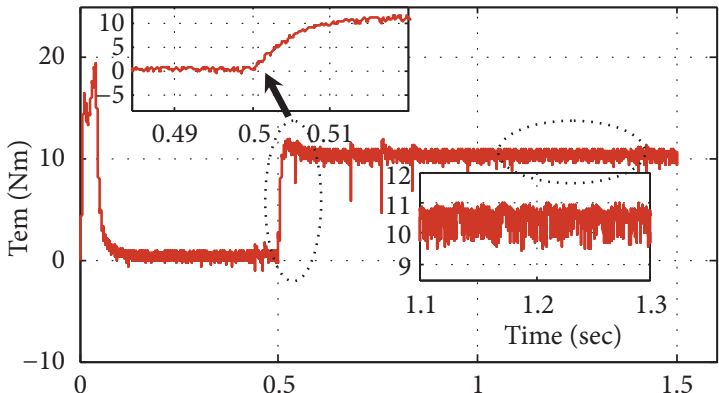

(a)

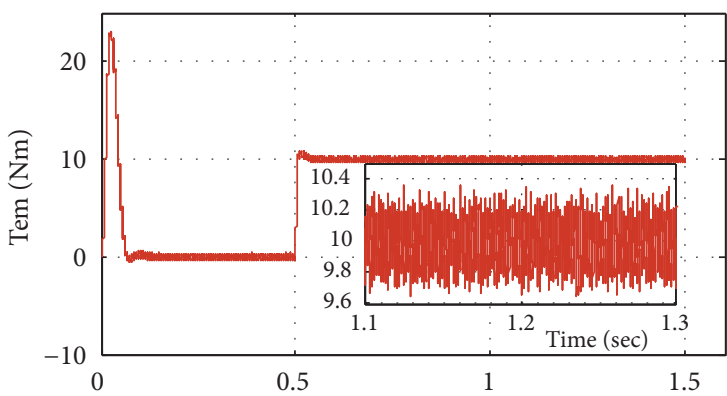

(c)

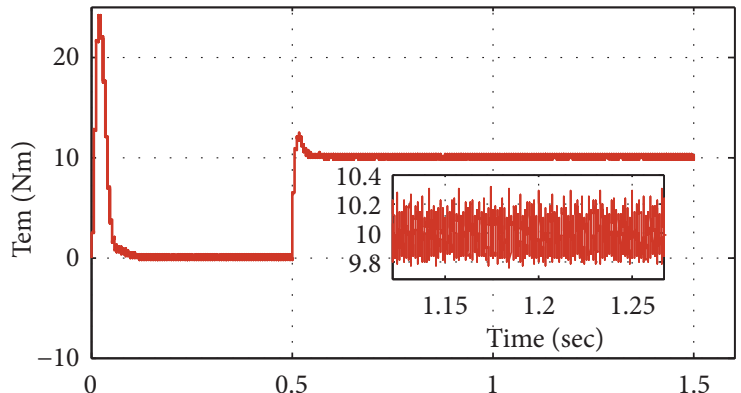

(b)

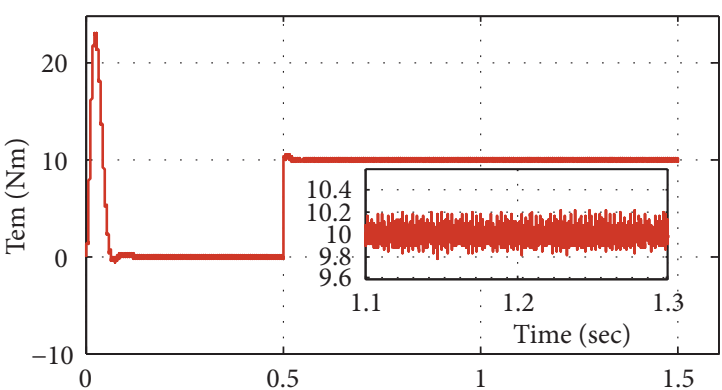

(d)

FIGURE 10: Torque response for (a) conventional DTC, (b) SVM-DTC-IOFL based on PI controller, (c) SVM-DTC-IOFL based on FOSMC, and (d) SVM-DTC-IOFL based on STSC.

depicted in Figure 14(a), ZOOM). The torque has a fast response and low ripples even at a locked rotor and a rated load. A comparative study is provided in Tables 2 and 3.
4.2. Performance Analyzes of SVM-DTC-IOFL Based on STSC at Low Speed $(10 \mathrm{Rad} / \mathrm{Sec})$. To show the performances of the SVM-DTC-IOFL-STSC at a low speed, a simulation study is carried out. In this study, the reference speed and the load 


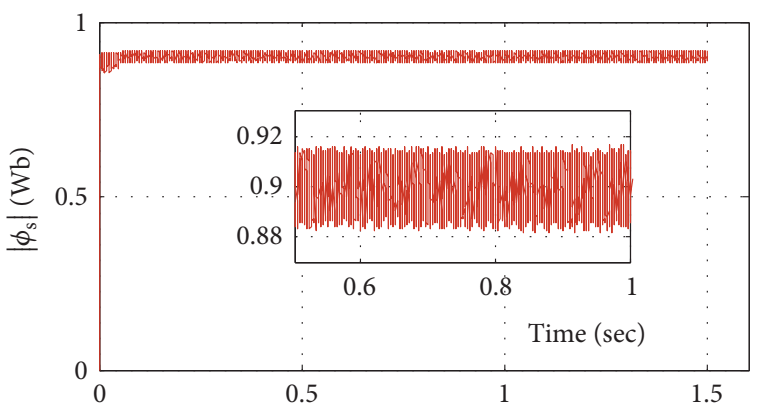

(a)

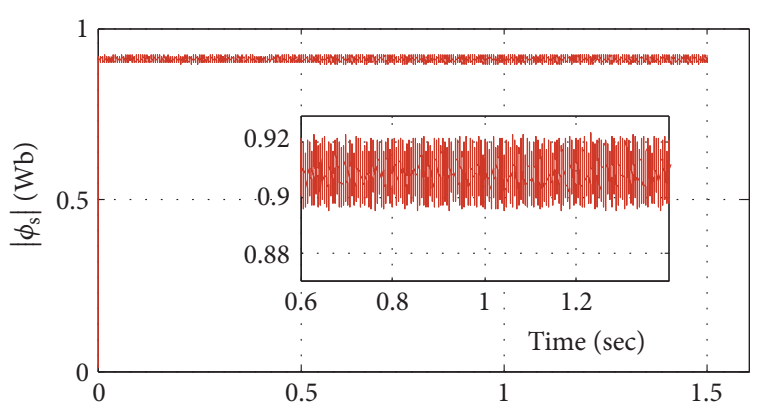

(c)

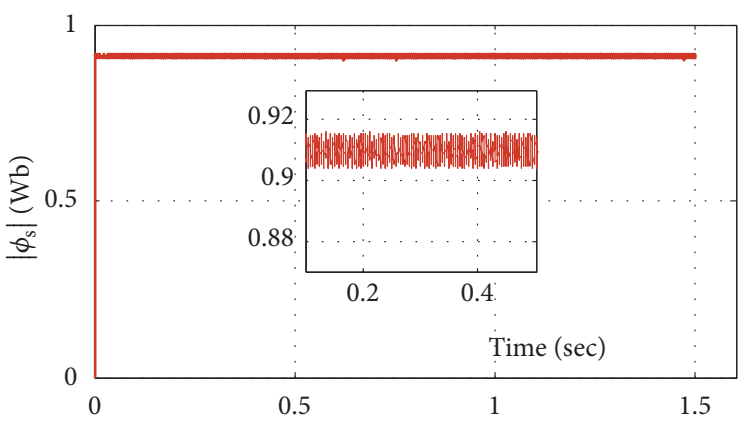

(b)

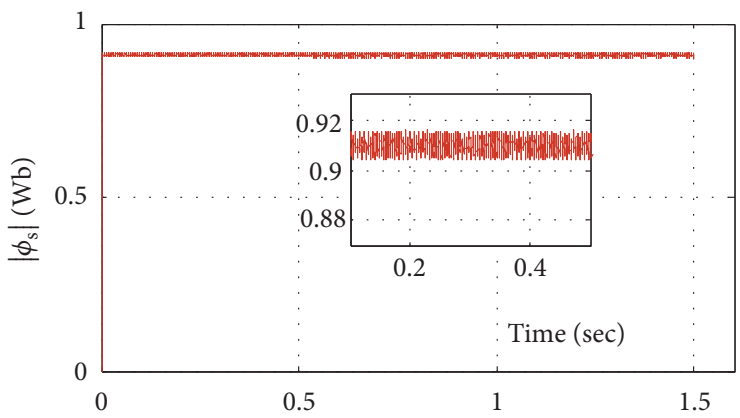

(d)

FIgURE 11: Norm of the Stator flux for (a) conventional DTC, (b) SVM-DTC-IOFL based on PI controller, (c) SVM-DTC-IOFL based on FOSMC, and (d) SVM-DTC-IOFL based on STSC.

TABLE 2: Performance analysis in terms of dynamics.

\begin{tabular}{lcccc}
\hline & Conventional DTC & $\begin{array}{c}\text { SVM-DTC-IOFL } \\
\text { based on PI }\end{array}$ & $\begin{array}{c}\text { SVM-DTC-IOFL } \\
\text { based on FOSMSC }\end{array}$ & $\begin{array}{c}\text { SVM-DTC-IOFL } \\
\text { based on STSC }\end{array}$ \\
\hline $\begin{array}{l}\text { Speed response time (sec) } \\
\begin{array}{l}\text { Speed dropping when load } \\
\text { is applied (rad/sec) }\end{array}\end{array}$ & 0.125 & 0.1 & 0.07 & 0.06 \\
$\begin{array}{l}\text { Torque response time when } \\
\text { load is applied }(\mathrm{sec})\end{array}$ & $0.86(2.57 \%)$ & $3(2 \%)$ & $0.3(0.833 \%)$ & $0.5(0.33 \%)$ \\
\hline
\end{tabular}

TABle 3: Performances analysis in terms of ripples.

\begin{tabular}{lcccc}
\hline & Conventional DTC & $\begin{array}{c}\text { SVM-DTC-IOFL } \\
\text { based on PI }\end{array}$ & $\begin{array}{c}\text { SVM-DTC-IOFL } \\
\text { based on FOSMSC }\end{array}$ & $\begin{array}{c}\text { SVM-DTC-IOFL } \\
\text { based on STSC }\end{array}$ \\
\hline $\mathrm{T}_{\mathrm{em}}(\mathrm{Nm})$ ripples & $1.4(14 \%)$ & $0.475(4.75 \%)$ & 0.6 & $0.35(3.5 \%)$ \\
$\phi(\mathrm{Wb})$ ripples & $0.03(3.33 \%)$ & $0.016(1.758 \%)$ & 0.02 & $0.01(1.098 \%)$ \\
\hline
\end{tabular}

torque are equal to $10 \mathrm{rad} / \mathrm{sec}$ and $10 \mathrm{Nm}$, respectively. The load torque is applied at $\mathrm{t}=10 \mathrm{Nm}$. The obtained results are given by the Figures 15, 16, 17, and 18.

Figure 15 illustrates the rotor speed responses for the three control strategies: the conventional DTC, the SVM-DTCIOFL based on PI controller, and the SVM-DTC-IOFL based on STSC at a low-speed operation. In this test, the reference speed is equal to $10 \mathrm{rad} / \mathrm{sec}$ and the rated load torque equal to $10 \mathrm{Nm}$ is applied at $\mathrm{t}=0.5 \mathrm{~s}$. It can be noticed clearly that the SVM-DTC-IOFL based on STSC offers good dynamics, as highlighted in Figure 15(c), but with a PI controller, the rotor speed presents some fluctuation, as represented in
Figure 15(b). The speed fluctuations are important in the conventional DTC, as given in Figure 15(a). The torque responses for the three control approaches are depicted in Figure 16. It can be seen that the low speed operation raises the torque ripples as shown in Figure 16(a). However, using the SVM-DTC-IOFL based on STSC offers a torque response with low ripples, as demonstrated by Figure 16(c). Figure 17 illustrates the evolution of the stator flux norm at a low speed. Referring to Figure 17(a), we can notice that the stator flux has high ripples and fluctuations. The ripples will be lower when the IM is controlled utilizing the SVM-DTC-IOFL with a PI controller and the SVM-DTC-IOFL with an STSC 


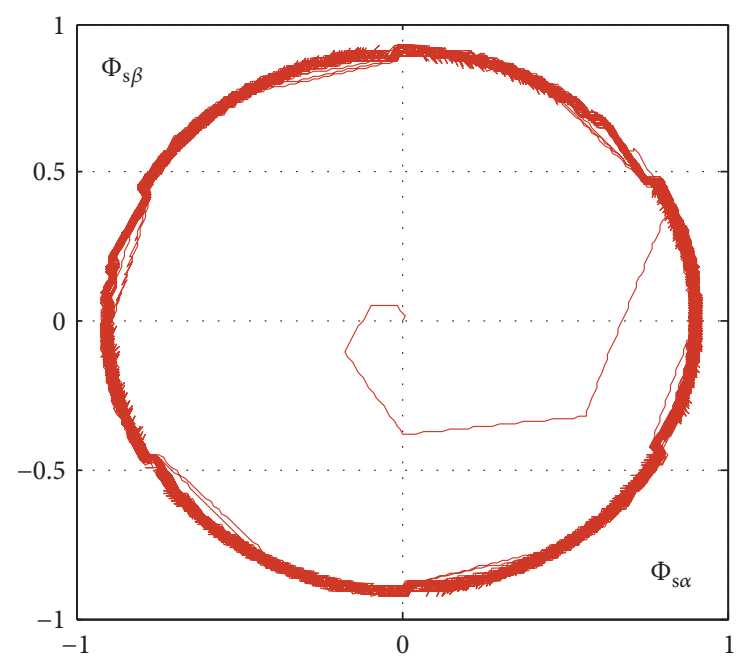

(a)

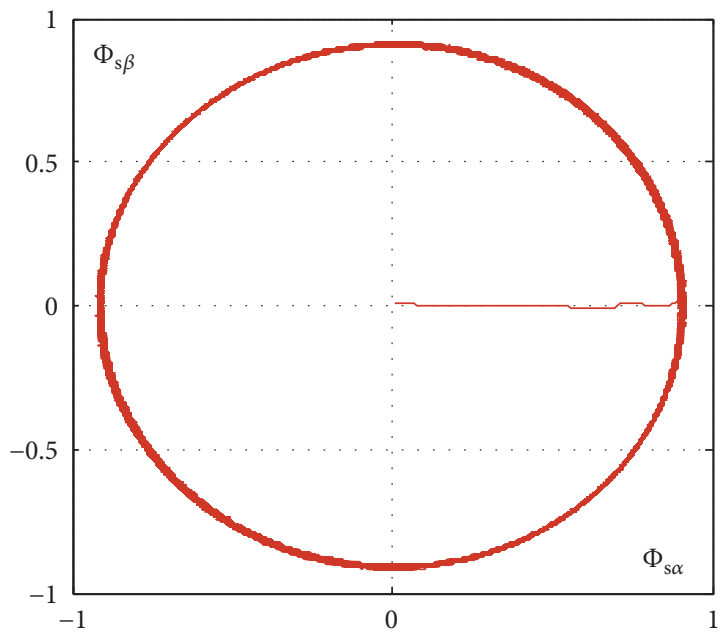

(c)

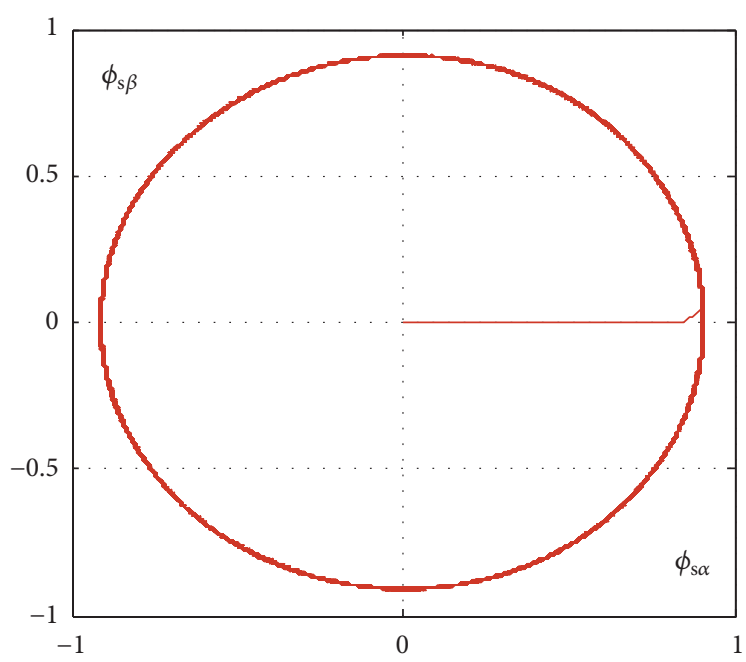

(b)

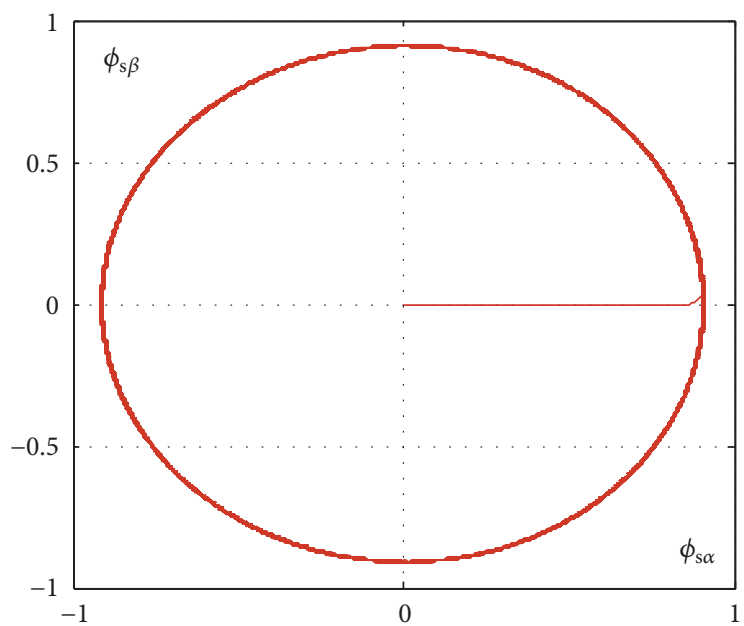

(d)

FIGURE 12: Stator flux trajectory for (a) conventional DTC, (b) SVM-DTC-IOFL based on PI controller, (c) SVM-DTC-IOFL based on FOSMC, and (d) SVM-DTC-IOFL based on STSC.

(see Figures 17(b) and 17(c)). The circular shape represented by the extremity of the stator flux vector under the three control strategies is given by Figures 18(a), 18(b), and 18(c). Figures 18(b) and 18(c) confirm the superiority of the SVMDTC-IOFL relative to the conventional DTC.

\subsection{Test Robustness at Low Speed and with Variation in Stator} Resistance. This test shows a comparative study between the SVM-DTC-IOFL based on STSC and the conventional DTC under a stator resistance variation. During the operation, the stator resistance goes up by $50 \%$ at $t=1 \mathrm{~s}$ with $7.5 \mathrm{rad} / \mathrm{sec}$ (5\% of rated speed) as a speed reference. The load torque is introduced at $\mathrm{t}=0.5 \mathrm{~s}$. Figures 19 and 20 depict the evolution of the stator flux norm and the rotor speed response under the variation in stator resistance. It can be noticed that the obtained results confirm the robustness of the SVM-DTCIOFL with an STSC compared with the conventional DTC. The effect of the stator resistance variation is very low and negligible under the SVM-DTC-IOFL based on STSC, as demonstrated by Figures 19(b) and 20(b).

A brief comparison between the conventional DTC, the SVM-DTC-IOFL based on STSC, and the Indirect Rotor Field-oriented Control (IRFOC) is illustrated in Table 4. This comparison integrates different criteria such as dynamics, stability properties, the commutation frequency, and the robustness under parameter variations.

\section{FPGA Implementation}

5.1. Synthesis Results. After designing and simulating the control algorithm, it possible to generate the VHDL code and determine the synthesis results utilizing the Xilinx ISE tool. During the hardware implementation of the proposed approaches, the used resources from the FPGA surface are presented in Table 5. 


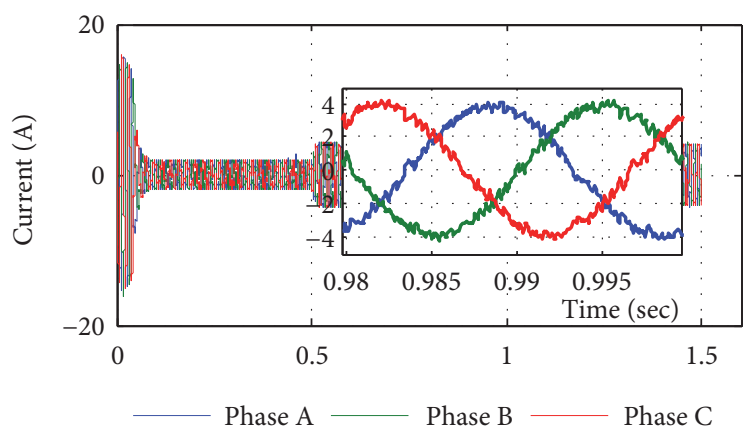

(a)

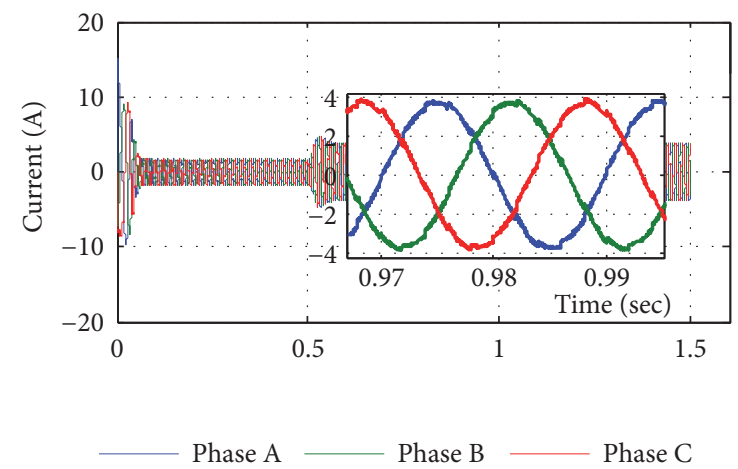

(c)

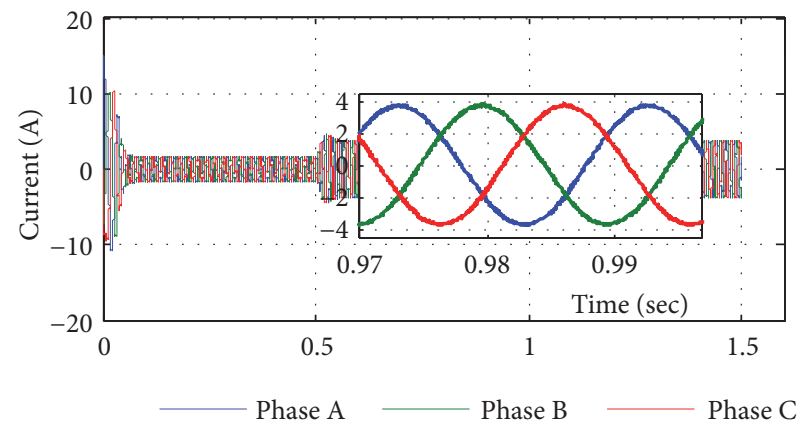

(b)

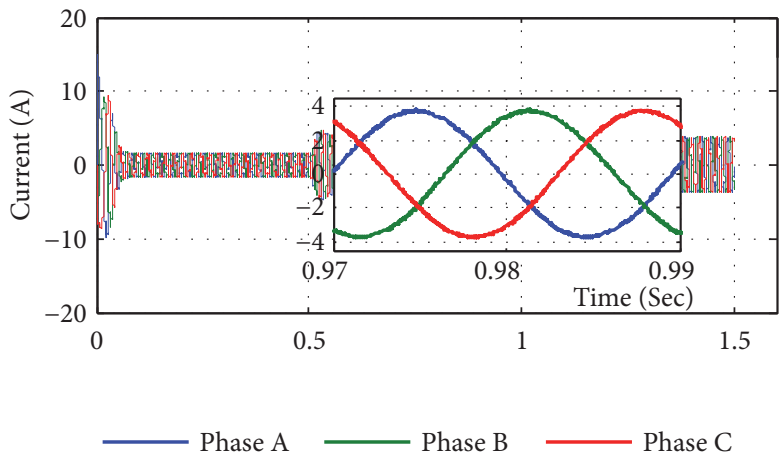

(d)

FIGURE 13: Three phase stator current for (a) conventional DTC, (b) SVM-DTC-IOFL based on PI controller, (c) SVM-DTC-IOFL based on FOSMC, and (d) SVM-DTC-IOFL based on STSC.

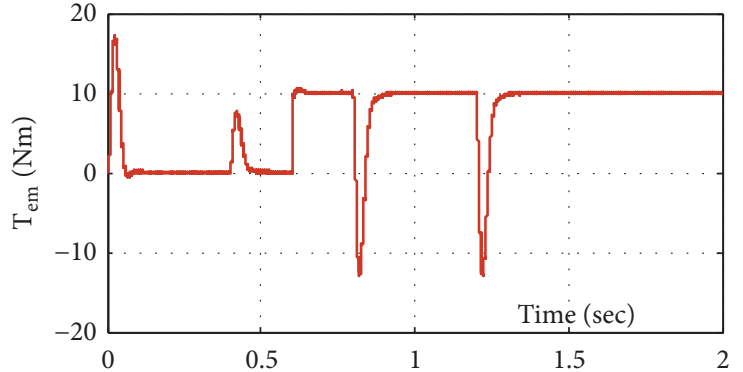

(a)

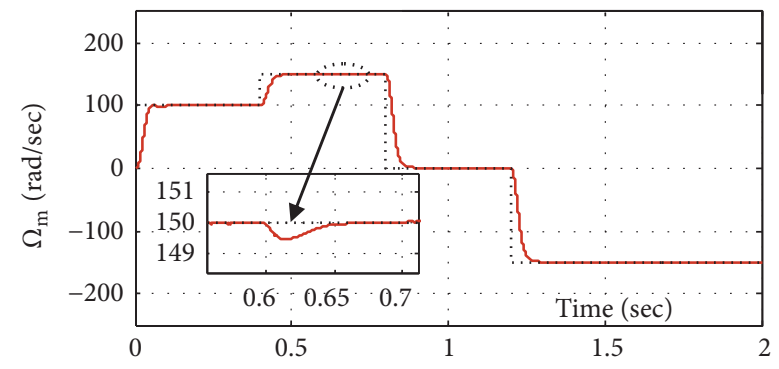

Actual speed reference speed

(b)

FIGURE 14: Speed response under SVM-DTC-IOFL based on STSC for different speed regions.

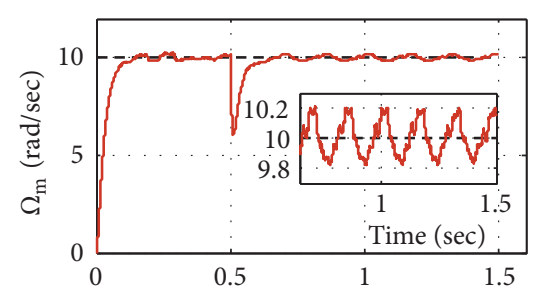

(a)

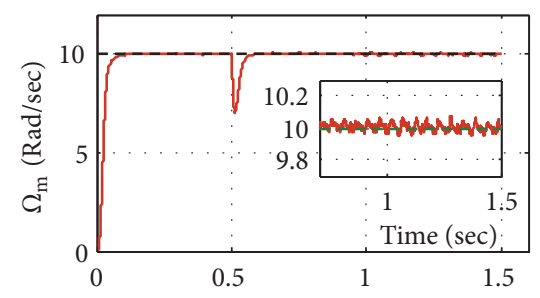

(b)

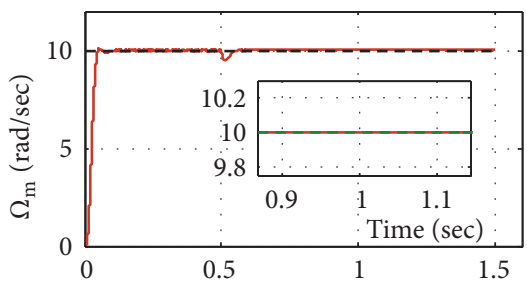

(c)

FIGURE 15: Speed response for (a) conventional DTC, (b) SVM-DTC-IOFL based on PI, and (c) SVM-DTC-IOFL based on STSC. 


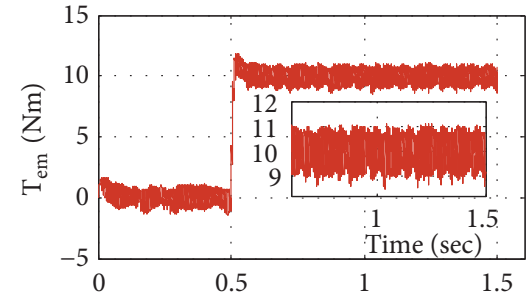

(a)

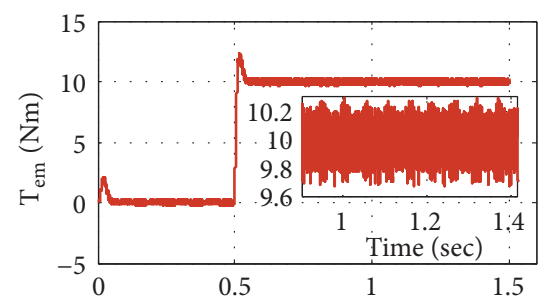

(b)

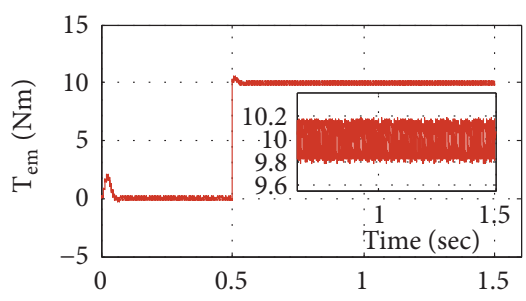

(c)

FIGURE 16: Torque response for (a) conventional DTC, (b) SVM-DTC-IOFL based on PI, and (c) SVM-DTC-IOFL based on STSC.

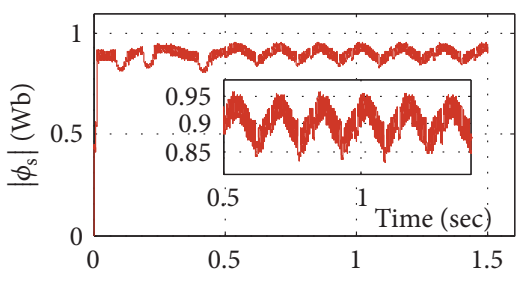

(a)

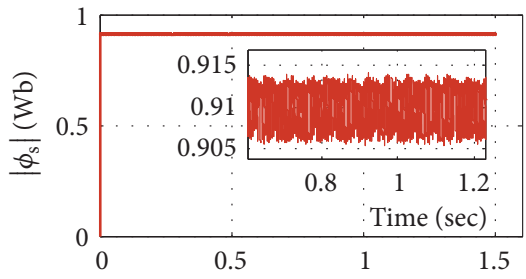

(b)

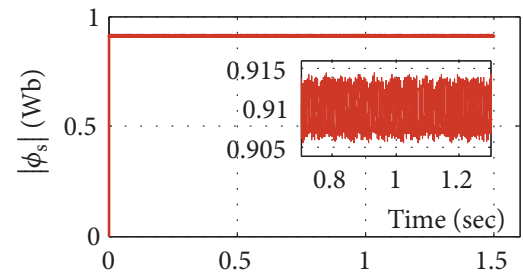

(c)

FIgURE 17: Norm of the Stator flux for (a) conventional DTC, (b) SVM-DTC-IOFL based PI, and (c) SVM-DTC-IOFL based on STSC.

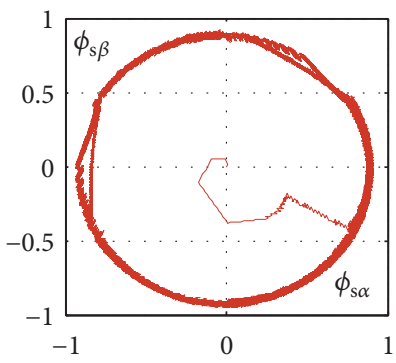

(a)

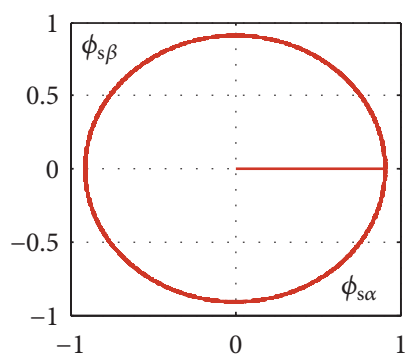

(b)

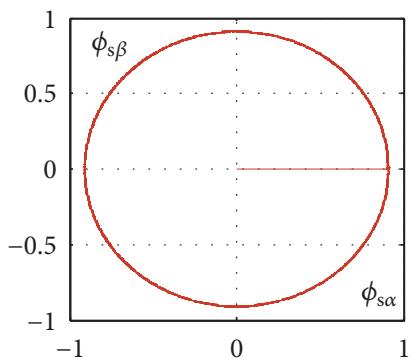

(c)

FIGURE 18: Stator flux trajectory for (a) conventional DTC, (b) SVM-DTC-IOFL based on PI, and (c) SVM-DTC-IOFL based on STSC.

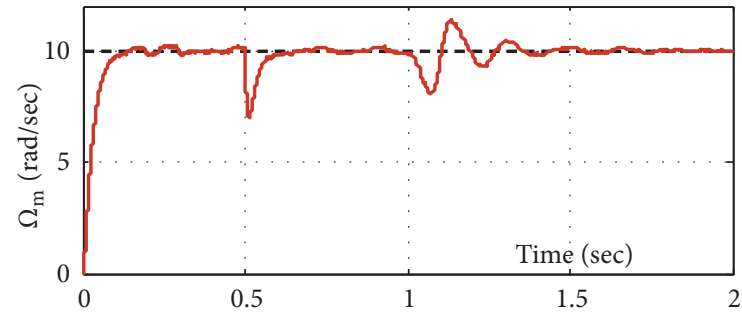

(a)

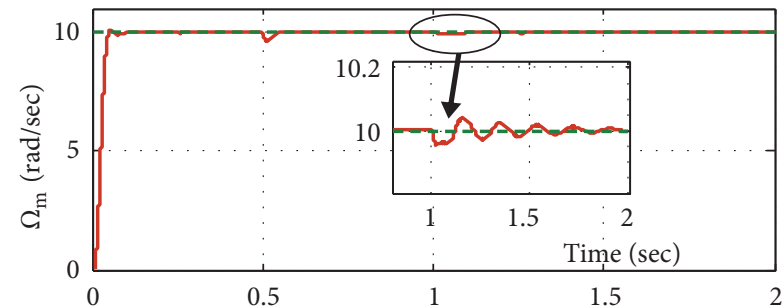

(b)

FiguRE 19: Rotor speed evolution with stator resistance variation (Rs increases by $50 \%$ at $\mathrm{t}=1 \mathrm{sec}$ at low speed region: $7.5 \mathrm{rad} / \mathrm{sec}$ ): (a) conventional DTC and (b) SVM-DTC-IOFL based on STSC.

TABLE 4: A comparative study between different control schemes.

\begin{tabular}{lccc}
\hline & IRFOC & Conventional DTC & SVM-DTC-IOFL-STSC \\
\hline Commutation frequency & Fixed & Variable & Fixed \\
$\begin{array}{l}\text { Dynamics } \\
\text { Stability properties }\end{array}$ & Low & good & excellent \\
$\begin{array}{l}\text { Robustness under } \\
\text { parameters variations }\end{array}$ & Low & Low & High \\
\end{tabular}




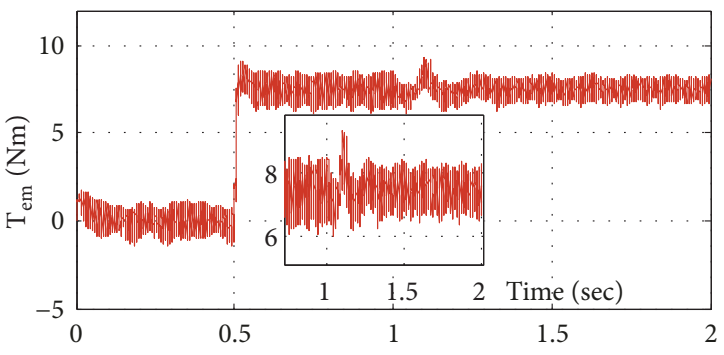

(a)

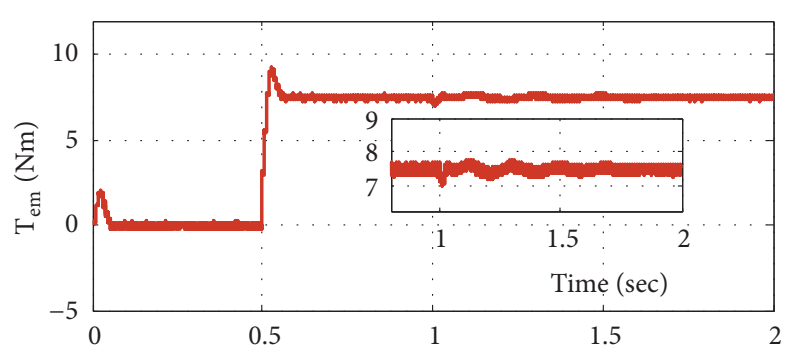

(b)

FIGURE 20: Torque evolution with stator resistance variation (Rs increased by $50 \%$ at $\mathrm{t}=1 \mathrm{sec}$ at low speed region: $7.5 \mathrm{rad} / \mathrm{sec}$ ): (a) conventional DTC and (b) SVM-DTC-IOFL-STSC.

TABLE 5: Utilized resources from FPGA surface.

\begin{tabular}{|c|c|c|c|c|c|}
\hline & Used with DTC & $\begin{array}{l}\text { Utilization for } \\
\text { DTC }\end{array}$ & $\begin{array}{c}\text { Used with } \\
\text { SVM-DTC-IOFL based } \\
\text { on STSC }\end{array}$ & Available & $\begin{array}{c}\text { Utilization for } \\
\text { SVM-DTC-IOFL based on } \\
\text { STSC }\end{array}$ \\
\hline $\begin{array}{l}\text { Number of bonded } \\
\text { IOBs }\end{array}$ & 13 & $2 \%$ & 13 & 640 & $2 \%$ \\
\hline Number of Slices & 1344 & $3 \%$ & 3966 & 44800 & $9 \%$ \\
\hline $\begin{array}{l}\text { Number of } \\
\text { MULT18X18s } \\
\end{array}$ & 16 & $12 \%$ & 41 & 128 & $3 \%$ \\
\hline $\begin{array}{l}\text { Maximum Clock } \\
\text { Frequency }\end{array}$ & & & $35.13 \mathrm{MHz}$ & & \\
\hline
\end{tabular}

TABLE 6: FPGA Performances: Execution time of SVM-DTC-IOFL with STSC.

\begin{tabular}{lcc}
\hline Module & Latency & Execution Time $(\mu \mathrm{s})$ \\
\hline ADC interface & - & $\mathrm{t}_{\mathrm{ADC}}=2.2 \mu \mathrm{s}$ \\
\hline Speed sensor interface & 4 & $\mathrm{t}_{\mathrm{s}}=0.04 \mu \mathrm{s}$ \\
\hline Concordia & 6 & $\mathrm{t}_{\mathrm{C}}=0.06 \mu \mathrm{s}$ \\
\hline Stator flux and torque estimator & 16 & $\mathrm{t}_{\mathrm{E}}=0.16 \mu \mathrm{s}$ \\
\hline STSC speed controller & 16 & $\mathrm{~T}_{\text {STSC}}=0.16 \mu \mathrm{s}$ \\
\hline OFL & 26 & $\mathrm{~T}_{\text {IOFL }}=0.26 \mu \mathrm{s}$ \\
\hline SVM & 14 & $\mathrm{t}_{\mathrm{SVM}}=0.14 \mu \mathrm{s}$ \\
\hline Total Control Time: $\mathrm{T}_{\mathrm{c}}=\mathrm{t}_{\mathrm{ADC}}+\mathrm{t}_{\mathrm{E}}+\mathrm{t}_{\mathrm{STSC}}+\mathrm{t}_{\mathrm{IOFL}}+\mathrm{t}_{\mathrm{SVM}}$ & & $\mathrm{T}_{\mathrm{ex}}=3.02 \mu \mathrm{s}$ \\
\hline
\end{tabular}

The obtained FPGA performances in terms of execution time of the designed SVM-DTC-IOFL with STSC hardware architecture are given in Table 6.

Referring to Table 6 , the total control time is evaluated by $3.02 \mu \mathrm{s}$. This offers the possibility of choosing a sampling period equal to $5 \mu \mathrm{s}$, which is equivalent to a sampling frequency equal to $200 \mathrm{kHz}$. The FPGA considerably reduces the period of the system and eliminates the time delay in the control loop, but utilizing the software solutions the execution time is important and evaluated by tens or even hundreds of microseconds [74, 75]. In [76], the execution time of a control algorithm using a DSP and an FPGA was equal to $66 \mu \mathrm{s}$ and $6 \mu \mathrm{s}$, respectively. This demonstrates the high processing speed of the FPGA thanks to its parallel processing. The effect of the execution time on the control performance was mentioned in [77], where the stator current harmonics increased with the growth of the execution time. In fact, when the execution time is equal to $2.64 \mu \mathrm{s}$ and
$50 \mu \mathrm{s}$, the total harmonic distortions will be equal to $8.4 \%$ and $11.1 \%$, respectively. A comparative study with other work about the DTC implemented on an FPGA is presented in Table 7. Figure 21 shows the sequential timing diagram of the control structure. At the beginning of each sampling period, the ADC interface module activates the two converters for the current acquisition simultaneously. Then, after a delay conversion from analog to digital $t_{\mathrm{ADC}}$, the control module SVM-DTC-IOFL based on STSC is activated.

5.2. Experimentation. The simulation results demonstrate the superiority of the proposed SVM-DTC-IOFL based on STSC relative to the other control strategy. The experimental validation of the proposed strategy is done in the laboratory utilizing an FPGA Virtex 5-ML507 which includes $100 \mathrm{MHz}$ oscillator. The experimental test bench integrates a squirrel cage induction motor, a Semikron voltage converter, a magnetic powder brake, an electronic board based on two sensors 


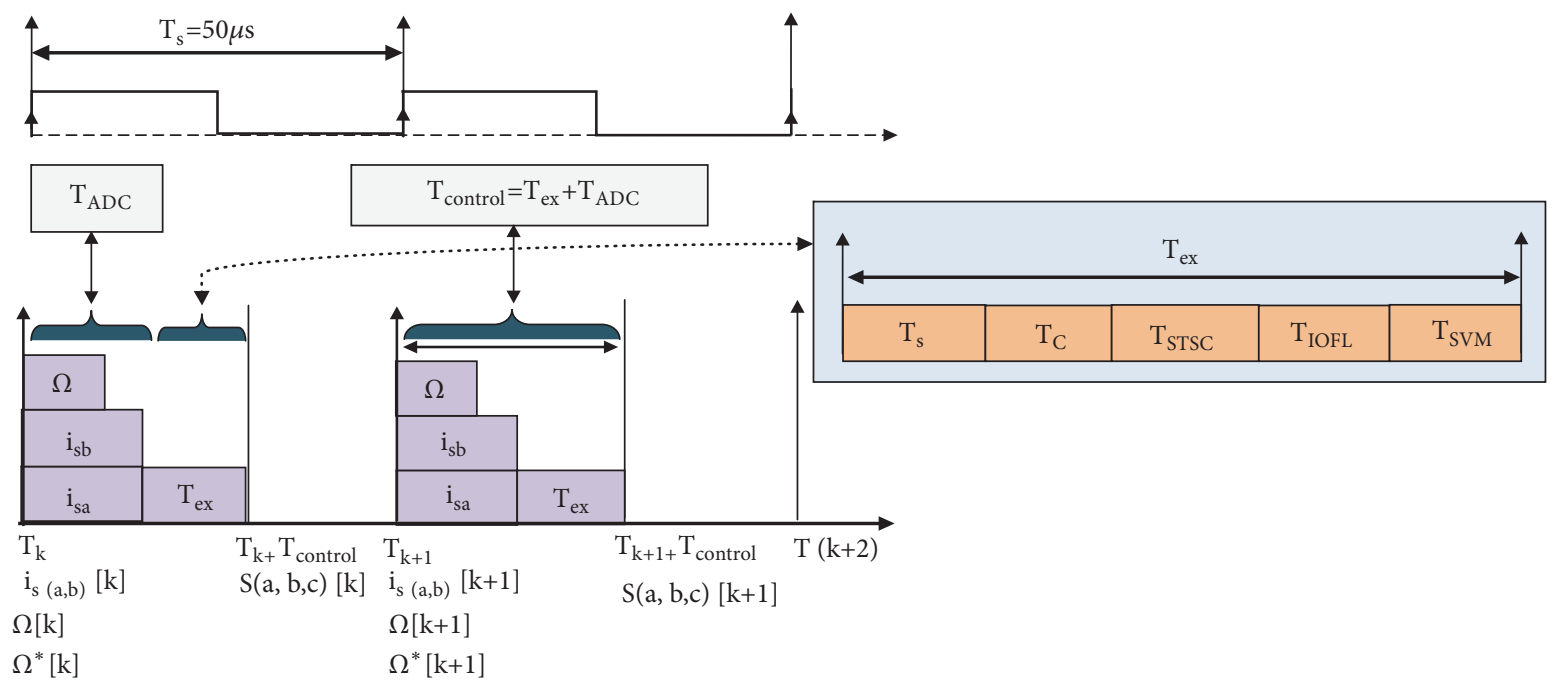

FIGURE 21: Sequential timing diagram of the control structure SVM-DTC-IOFL based on STSC.

TABLE 7: Comparison in terms of sampling frequency.

\begin{tabular}{llr}
\hline Reference & & DTC sampling frequency $(\mathrm{kHz})$ \\
\hline Proposed SVM-DTC-IOFL based on STSC & & 200 \\
\hline Utsumi [57] & Type A controller & 20 \\
& Type B controller & 40 \\
\hline Llor [58] & & 40 \\
\hline
\end{tabular}

TABLE 8: Induction machine parameters.

\begin{tabular}{lccc}
\hline Parameter & Value & Parameter & Value \\
\hline power $(\mathrm{kW})$ & 1.5 & Rotor resistance $(\Omega)$ & 4.282 \\
Voltage $(\mathrm{V})$ & $230 / 400$ & Stator inductance $(\mathrm{H})$ & 0.464 \\
Frequency $(\mathrm{Hz})$ & 50 & Rotor inductance $(\mathrm{H})$ & 0.464 \\
Pole pair & 2 & Mutual inductance $(\mathrm{H})$ & 0.4417 \\
Stator resistance $(\Omega)$ & 5.717 & Rated speed $(\mathrm{rpm})$ & 1435 \\
\hline
\end{tabular}

TABLE 9: Gains of the control schemes.

\begin{tabular}{lc}
\hline & Gains / Values \\
\hline IOFL controller & $k_{1}=8000 ; k_{2}=8000$ \\
STSC controller & $\delta_{\Omega}=1.2 ; \mu_{\Omega}=11$ \\
FOSMSC & $\lambda=25 ; K=5$ \\
PI speed controller & $\mathrm{K}_{\mathrm{p}}=0.825 ; \mathrm{K}_{\mathrm{i}}=35$ \\
\hline
\end{tabular}

LA25NP for stator current measurement, an electronic board based on an ADS8509 converter for analog to digital conversion of the stator current, and an inverter interface circuit board to create the dealt time. The block diagram of the test bench and its real view are given by Figure 22. The hardware control system includes the SVM-DTC-IOFL based on STSC, a serial interface, an ADC interface, and incremental coder interface in one FPGA chip. The results were recorded using the RS232 and plotted within MATLAB.

The obtained experimental results of the proposed SVMDTC-IOFL based on STSC are given by Figures 23(a), 23(b),
TABLE 10: The relationship between $\xi$ and $\omega_{0} t_{\text {rep }}$.

\begin{tabular}{lc}
\hline$\xi$ & $\omega_{0} \mathrm{t}_{\text {rep }}$ \\
\hline 0.4 & 7.7 \\
0.5 & 5.3 \\
0.6 & 5.2 \\
0.7 & 3 \\
1 & 4.75 \\
\hline
\end{tabular}

23(c), and 23(d) which are the control signals generated by the inverter interface circuit board, the stator current in the Concordia reference measured by the current sensors, the rotor speed, and the stator current $i_{s \alpha}$, respectively. The reference of the electric speed is equal to $300 \mathrm{rad} / \mathrm{sec}$. It is clearly seen that the proposed SVM-DTC-IOFL based on STSC scheme offer a good performances in terms of fast speed response, good tracking with very low deviation under the load disturbances and with ripples in steady-state, as 


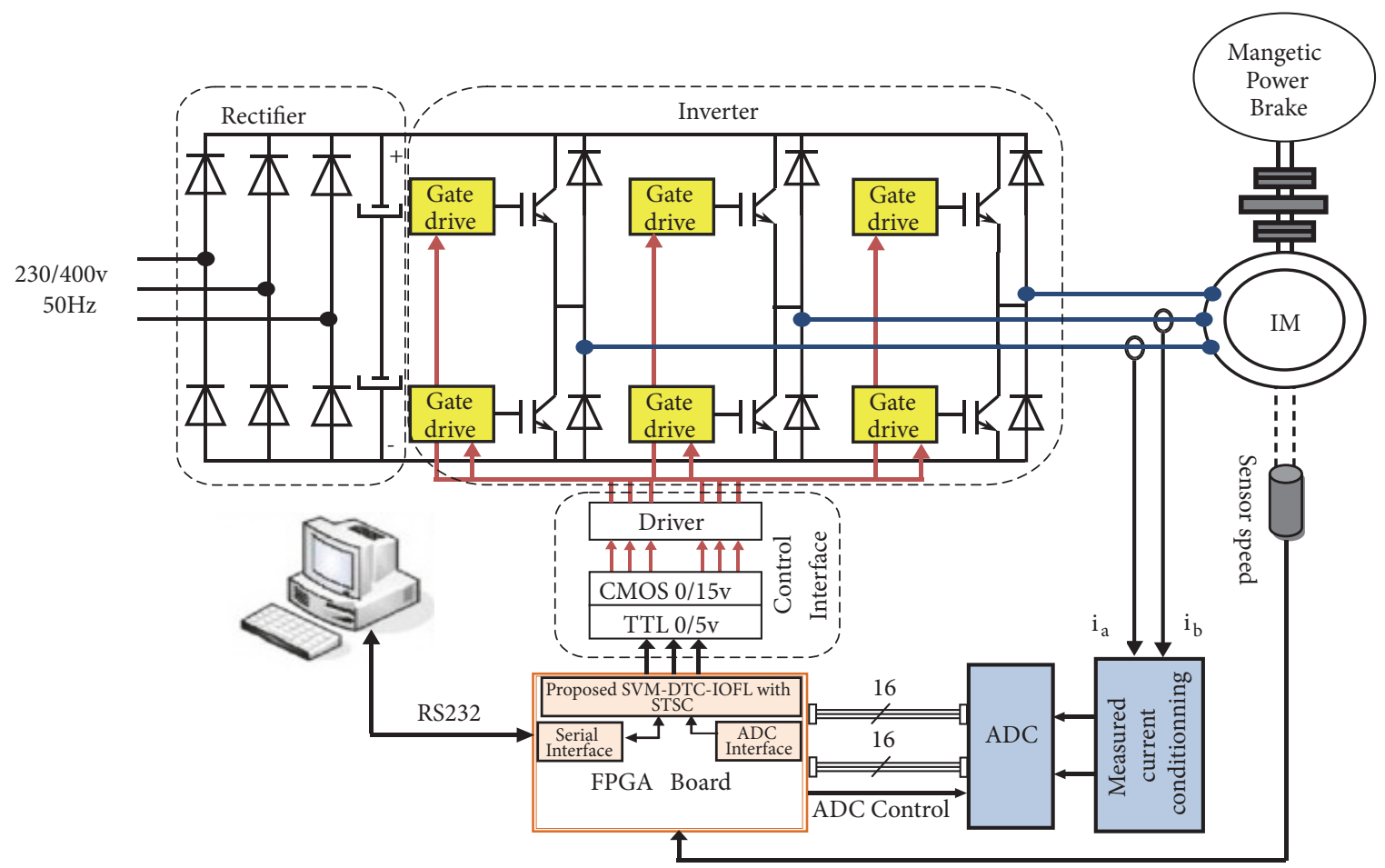

(a)
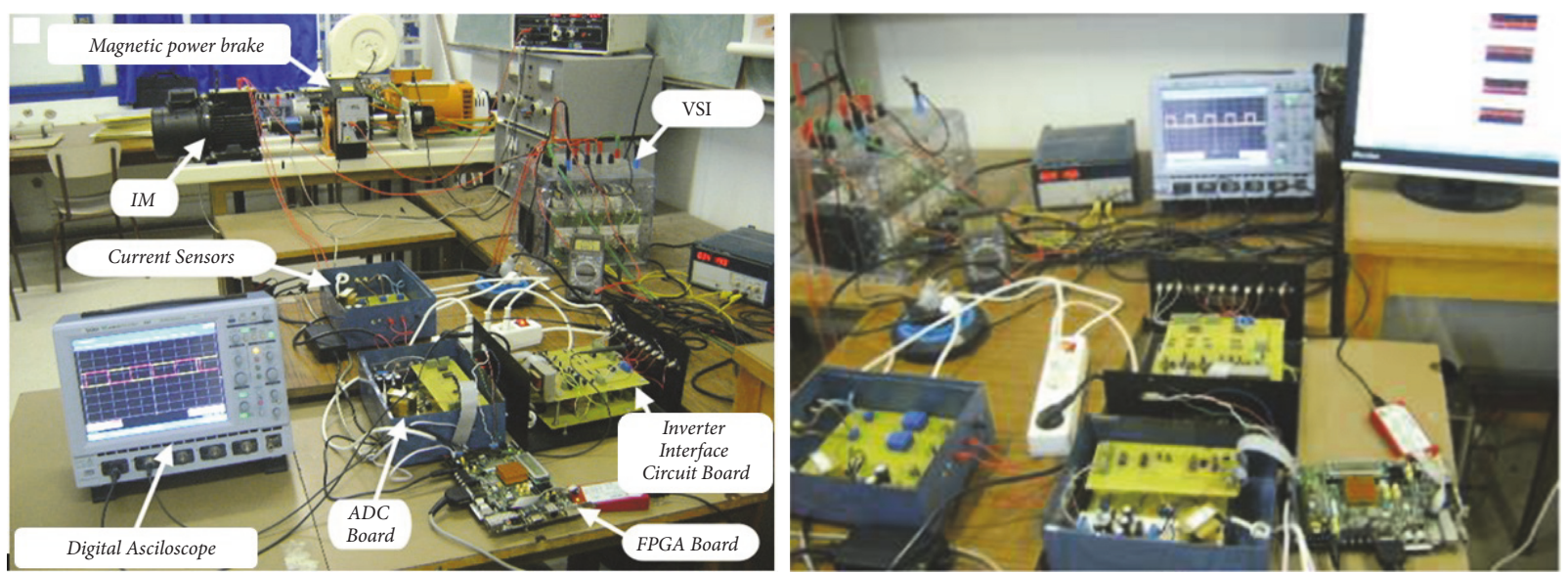

(b)

Figure 22: Experimental system: (a) block diagram of test bench and (b) real view of bench.

demonstrated by Figure 23(c). Figure 23(d) demonstrate that the stator current the stator current has a good sinusoid waveform and low harmonics. Figures 24(a) and 24(b) presents the evolution of the stator flux norm and the electromagnetic torque. We can easily notice that the proposed approach reaches better performances in terms of ripples reduction and good tracking.

The experimental results are similar to those obtained by digital simulation; the main difference between these results can be justified by many reasons, like the ideal simulation under the Matlab environment, the dead times between the control signals of the inverter, and the losses in the motor which are neglected in the modeling step.
These results confirm the IM performances controlled by the proposed SVM-DTC-IOFL based on STSC. The very fast FPGA computation time allows obtaining much higher performance and overcoming the typical limitation of DSP sequential algorithms mentioned in [45].

\section{Conclusion}

In this paper, a performance improvement of the DTC of an IM drive utilizing the SVM technique and two nonlinear control strategies is presented. In order to solve the conventional DTC problems, like the torque ripples, the current distortion, and the variation in the switching frequency, the 


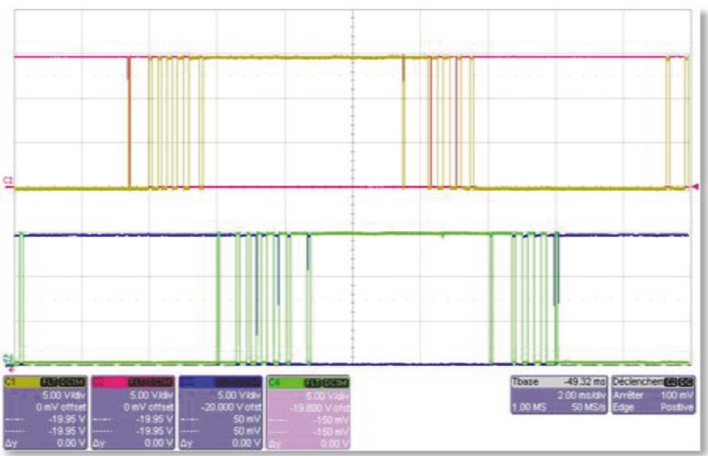

(a)

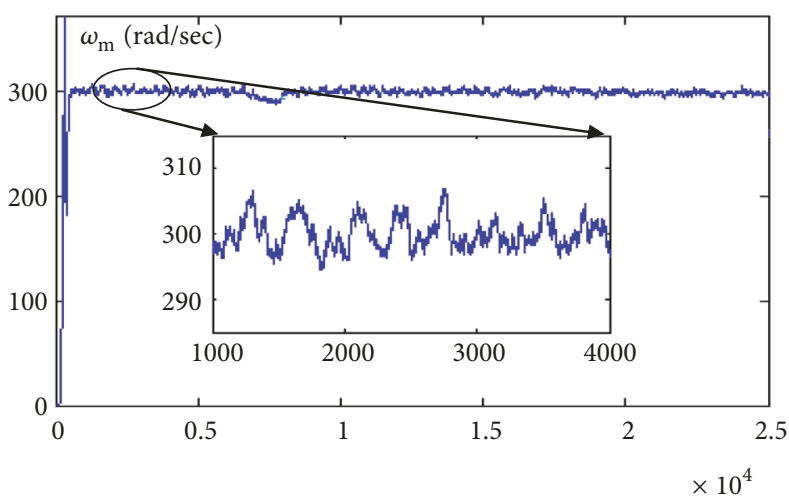

(c)

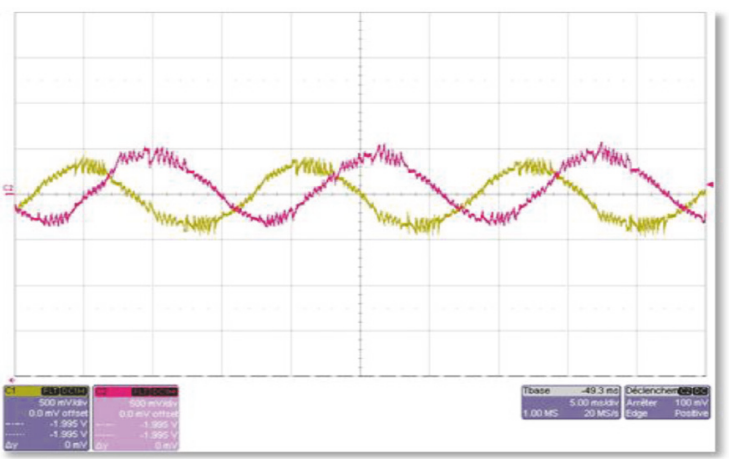

(b)

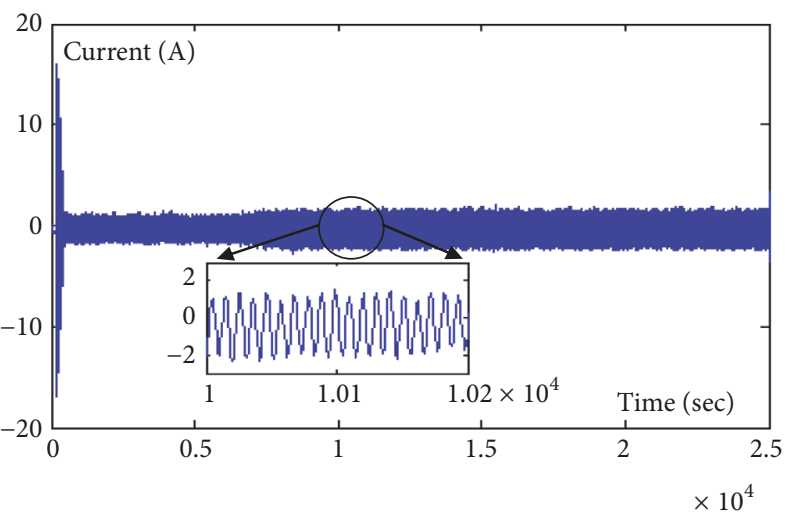

(d)

FIGURE 23: Experimental results of proposed SVM-DTC-IOFL based on STSC feeding an induction motor: (a) control signals generated by the inverter interface circuit board, (b) stator current in the Concordia reference measured by the current sensors, (c) rotor speed, and (d) stator current $i_{s \alpha}$.

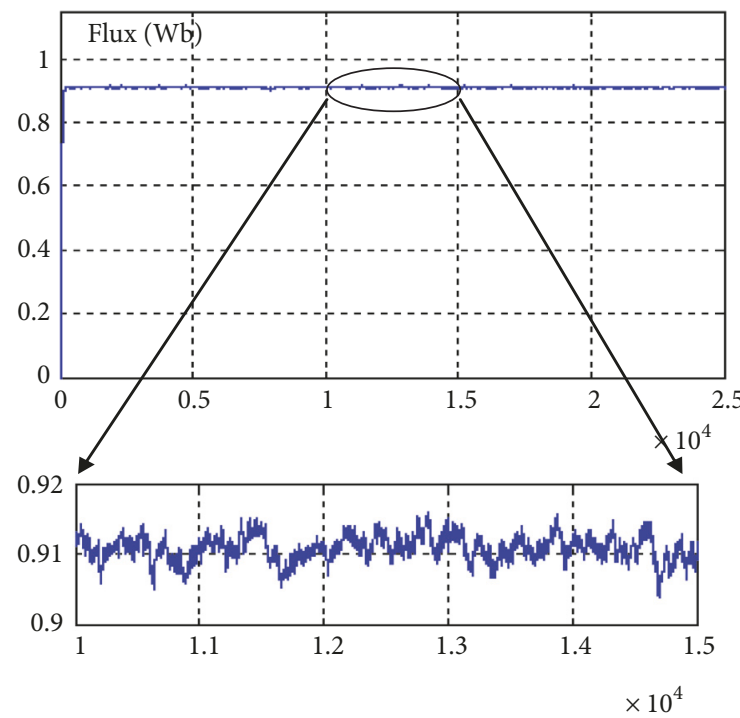

(a)

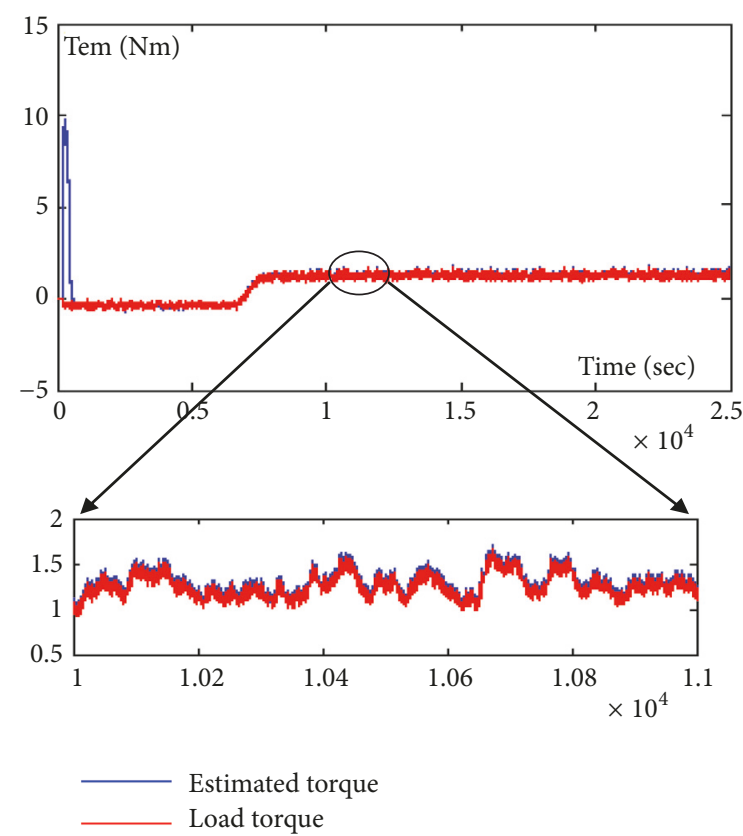

(b)

FIGURE 24: Experimental results of proposed SVM-DTC-IOFL based on STSC feeding an induction motor: (a) the norm of the stator flux and (b) the electromagnetic torque. 
SVM technique has been inserted in the DTC structure. The proposed scheme is known as the SVM-DTC. Then, the IOFL approach combined with the nonlinear secondorder sliding mode super-twisting algorithm was applied to achieve better speed tracking performance and to reject external disturbances. The stability of the proposed SVMDTC-IOFL with super twisting algorithm has been analyzed mathematically using Lyapunov stability theory.

A comparative study between the conventional DTC, the SVM-DTC-IOFL with PI speed controller, the SVM-DTCIOFL with FOSMSC, and the proposed SVM-DTC-IOFL with STSC is presented, which demonstrate the superiority of the proposed SVM-DTC-IOFL with STSC in terms of ripples reduction, robustness against the external load disturbances, fast dynamic response, and good tracking, and has reduced the complexity of the control scheme compared with the other control approaches. In addition, the second-order sliding mode speed controller has increased the robustness of the control approach against reference speed variation and external load disturbances. Moreover, this controller has been featured by its simple design and implementation.

The experimental validation of the proposed SVM-DTCIOFL with STSC algorithm has been carried out in the laboratory using an FPGA Virtex V ML507. The implementation on the FPGA is made utilizing the XSG tool. The obtained results are similar to those obtained by simulation. In the implementation step, the algorithm of the proposed approach is executed in very short time, thanks to the high degree of parallelism of the FPGA architecture. The low execution time reduces the delays in the control loop, which consequently decreases the current and torque harmonics and increases the induction motor service life. Finally, the robust SVM-DTCIOFL with a super twisting speed controller can be considered as a good solution to control the electrical motor drives.

For future works, it is interesting firstly to add a novel sliding mode speed observer for speed estimation which consequently reduces the control system cost and the rate of maintenance. Secondly, it is important to add a model based loss minimization strategy for the purpose of efficiency optimization. Thirdly, it is interesting extend the SVM-DTCIOFL with STSC algorithm for dynamic reconfiguration process and to use new digital solutions like Zync from Xilinx and Cyclone from Altera.

\section{Appendix}

See Tables 8, 9, and 10 .

\section{Nomenclature}

DTC: $\quad$ Direct torque control

SVM: $\quad$ Space vector modulation

IM: Induction motor

IOFL: Input-output feedback linearization

STSC: $\quad$ Super-twisting speed controller

SMC: $\quad$ Sliding mode control

FOSMSC: First-order sliding mode speed controller

XSG: $\quad$ Xilinx system generator

FPGA: $\quad$ Field programmable gate array
VHDL: VHSIC hardware description language

PI: $\quad$ proportional integral

IRFOC: Indirect rotor field oriented control

DSPACE: Digital signal processing and control engineering

DSP: Digital signal processor

Udc: Direct voltage to fed he inverter

$\mathrm{J}: \quad$ Inertia moment

$\Omega_{\mathrm{m}}: \quad$ Mechanical rotor speed

Tem: Electromagnetic torque

$\mathrm{f}: \quad$ Coefficient of friction

$\mathrm{T}_{1}$ : $\quad$ Load torque

Np: $\quad$ Number of the poles pairs

$\left(i_{s \alpha}, i_{s \beta}\right):$ Stator current components

$\left(\mathrm{v}_{\mathrm{s} \alpha}, \mathrm{v}_{\mathrm{s} \beta}\right)$ : Voltage vectors components

$\left(\phi_{\mathrm{s} \alpha}, \phi_{\mathrm{s} \beta}\right)$ : Stator flux vector components

$\left(\mathrm{R}_{\mathrm{r}}, \mathrm{R}_{\mathrm{s}}\right)$ : Rotor and stator resistance, respectively

$\left(\mathrm{L}_{\mathrm{r}}, \mathrm{L}_{\mathrm{s}}\right)$ : Rotor and stator inductance, respectively

$\left(\mathrm{T}_{\mathrm{r}}, \mathrm{T}_{\mathrm{s}}\right)$ : Rotor and stator time constants

$\omega_{\mathrm{r}}(\mathrm{rad} / \mathrm{s}):$ Electric rotor speed

$\sigma: \quad$ Blondel coefficient

$\mathrm{M}_{\mathrm{sr}}: \quad$ Mutual inductance.

\section{Data Availability}

The data used to support the findings of this study are available from the corresponding author upon request.

\section{Conflicts of Interest}

The authors declare that there are no conflicts of interest regarding the publication of this paper.

\section{References}

[1] I. Takahashi and T. Noguchi, "A new quick-response and high-efficiency control strategy of an induction motor ," IEEE Transactions on Industry Applications, vol. IA-22, no. 5, pp. 820827,1986

[2] M. Depenbrock, "Direct self-control (DSC) of inverter-fed induction machine," IEEE Transactions on Power Electronics, vol. 3, no. 4, pp. 420-429, 1988.

[3] J.-K. Kang and S.-K. Sul, "Analysis and prediction of inverter switching frequency in direct torque control of induction machine based on hysteresis bands and machine parameters," IEEE Transactions on Industrial Electronics, vol. 48, no. 3, pp. 545-553, 2001.

[4] M. Uddin and M. Hafeez, "FLC-based DTC scheme to improve the dynamic performance of an im drive," IEEE Transactions on Industry Applications, vol. 48, no. 2, pp. 823-831, 2012.

[5] K. Saber, G. Soufien, M. Abdellatif, and M. F. Mimouni, "Control with high performances based DTC strategy: FPGA implementation and experimental validation," European Power Electronics and Drives Journal, vol. 29, no. 2, pp. 82-98, 2019.

[6] K. Saber, G. Soufien, M. Abdellatif, and M. F. Mimouni, "Implementation on the FPGA of DTC-SVM based proportional integral and sliding mode controllers of an induction motor: a comparative study, Journal of Circuits, Systems, and Computers, vol. 26, no. 3, pp. 1-32, 2017. 
[7] A. Zaafouri, C. B. Regaya, H. B. Azza, and A. Châari, "DSPbased adaptive backstepping using the tracking errors for high-performance sensorless speed control of induction motor drive," ISA Transactions ${ }^{\circledR}$, vol. 60, pp. 333-347, 2016.

[8] V. Utkin, J. Guldner, and J. Shi, Sliding Mode Control in ElectroMechanical Systems, CRC Press, Taylor \& Francis, London, UK, 2009.

[9] F. Alonge, M. Cirrincione, M. Pucci, and A. Sferlazza, "Inputoutput feedback linearization control with on-line MRASbased inductor resistance estimation of linear induction motors including the dynamic end effects," IEEE Transactions on Industry Applications, vol. 52, no. 1, pp. 254-266, 2016.

[10] R. Yazdanpanah, J. Soltani, and G. R. Arab Markadeh, "Nonlinear torque and stator flux controller for induction motor drive based on adaptive input-output feedback linearization and sliding mode control," Energy Conversion and Management, vol. 49, no. 4, pp. 541-550, 2008.

[11] Y.-S. Choi, H. H. Choi, and J.-W. Jung, "Feedback linearization direct torque control with reduced torque and flux ripples for IPMSM drives," IEEE Transactions on Power Electronics, vol. 31, no. 5, pp. 3728-3737, 2016.

[12] C. Lascu, S. Jafarzadeh, M. S. Fadali, and F. Blaabjerg, "Direct torque control with feedback linearization for induction motor drives," IEEE Transactions on Power Electronics, vol. 32, no. 3, pp. 2072-2080, 2017.

[13] A. Saghafinia, H. W. Ping, M. N. Uddin, and K. S. Gaeid, "Adaptive fuzzy sliding-mode control into chattering-free im drive," IEEE Transactions on Industry Applications, vol. 51, no. 1, pp. 692-701, 2015.

[14] J. A. Burton and A. S. I. Zinober, "Continuous approximation of variable structure control," International Journal of Systems Science, vol. 17, no. 6, pp. 875-885, 1986.

[15] J. J. E. Slotine and W. Li, Applied Nonlinear Control, Prentice Hall, Englewood Cliffs, NJ, USA, 1991.

[16] F. Plestan, Y. Shtessel, V. Brégeault, and A. Poznyak, "New methodologies for adaptive sliding mode control," International Journal of Control, vol. 83, no. 9, pp. 1907-1919, 2010.

[17] J. Zhang, P. Shi, and Y. Xia, "Robust adaptive sliding-mode control for fuzzy systems with mismatched uncertainties," IEEE Transactions on Fuzzy Systems, vol. 18, no. 4, pp. 700-711, 2010.

[18] M. Ö. Efe, "Fractional order systems in industrial automation-a survey," IEEE Transactions on Industrial Informatics, vol. 7, no. 4, pp. 582-591, 2011.

[19] O. Keith and J. Spanier, The Fractional Calculus Theory and Applications of Differentiation and Integration to Arbitrary Order, vol. 111, Elsevier, 1974.

[20] Y. Tang, X. Zhang, D. Zhang, G. Zhao, and X. Guan, "Fractional order sliding mode controller design for antilock braking systems," Neurocomputing, vol. 111, pp. 122-130, 2013.

[21] A. J. Calderón, B. M. Vinagre, and V. Feliu, "Fractional order control strategies for power electronic buck converters," Signal Processing, vol. 86, no. 10, pp. 2803-2819, 2006.

[22] L. Ying, C. Y. Quan, A. Hyo-Sung, and P. Youguo, "Fractional order periodic adaptive learning compensation for cogging effect in PMSM position servo system," in Proceedings of the American Control Conference (ACC), pp. 937-942, St. Louis, Miss, USA, June 2009.

[23] H. Delavari, R. Ghaderi, A. Ranjbar, and S. Momani, "Fuzzy fractional order sliding mode controller for nonlinear systems," Communications in Nonlinear Science and Numerical Simulation, vol. 15, no. 4, pp. 963-978, 2010.
[24] A. Fayazi and H. Nabizadeh Rafsanjani, "Fractional order fuzzy sliding mod controller for robotic flexible joint manipulators," in Proceedings of the 9th IEEE International Conference on Control and Automation, ICCA 2011, pp. 1244-1249, Chile, December 2011.

[25] B. Zhang, Y. Pi, and Y. Luo, "Fractional order sliding-mode control based on parameters auto-tuning for velocity control of permanent magnet synchronous motor," ISA Transactions ${ }^{\circledR}$, vol. 51, no. 5, pp. 649-656, 2012.

[26] H. Liu, Y. Pan, S. Li, and Y. Chen, "Synchronization for fractional-order neural networks with full/under-actuation using fractional-order sliding mode control," International Journal of Machine Learning and Cybernetics, vol. 9, no. 7, pp. 12191232, 2018.

[27] J. Fei and X. Liang, "Adaptive backstepping fuzzy-neuralnetwork fractional order control of microgyroscope using nonsingular terminal sliding mode controller," Complexity, vol. 2018, Article ID 5246074, 12 pages, 2018.

[28] N. Liu and J. Fei, "Adaptive fractional sliding mode control of active power filter based on dual RBF neural networks," IEEE Access, vol. 5, pp. 27590-27598, 2017.

[29] D. Cao and J. Fei, "Adaptive fractional fuzzy sliding mode control for three-phase active power filter," IEEE Access, vol. 4, pp. 6645-6651, 2016.

[30] M. Ö. Efe, "Fractional order sliding mode control with reaching law approach," Turkish Journal of Electrical Engineering \& Computer Sciences, vol. 18, no. 5, pp. 731-747, 2010.

[31] A. Levant, "Higher-order sliding modes, differentiation and output-feedback control," International Journal of Control, vol. 76, no. 9-10, pp. 924-941, 2003.

[32] G. Bartolini, A. Ferrara, and E. Usai, "Chattering avoidance by second-order sliding mode control," IEEE Transactions on Automatic Control, vol. 43, no. 2, pp. 241-246, 1998.

[33] S. Di Gennaro, J. Rivera, and B. Castillo-Toledo, "Super-twisting sensorless control of permanent magnet synchronous motors," in Proceedings of the 2010 49th IEEE Conference on Decision and Control, CDC 2010, pp. 4018-4023, USA, December 2010.

[34] STMicroelectronics, Motor Control with STM32 ${ }^{\circledR} 32$-bit ARM ${ }^{\circledR}$ Based MCU, Printed in United Kingdom, 2011.

[35] K. Rao, D. J. Vaghela, and M. V. Gojiya, "Implementation of SPWM technique for 3- $\Phi$ VSI using STM32F4 discovery board interfaced with MATLAB," in Proceedings of the 1st IEEE International Conference on Power Electronics, Intelligent Control and Energy Systems, ICPEICES 2016, pp. 1-5, India, July 2016.

[36] S. Ozcira, N. Bekiroglu, and I. Senol, "Dynamic performance and analysis of direct torque control method based on DSP for PMSM drives," in Proceedings of the 1st International Conference on Renewable Energy Research and Applications, ICRERA 2012, pp. 1-5, Japan, November 2012.

[37] S. M. A. Cruz, H. A. Toliyat, and A. J. M. Cardoso, "DSP implementation of the multiple reference frames theory for the diagnosis of stator faults in a DTC induction motor drive," IEEE Transactions on Energy Conversion, vol. 20, no. 2, pp. 329-335, 2005.

[38] S. K. Abed and M. S. Khanniche, "Microprocessor-based induction motor drive system using sliding mode control," in Proceedings of the 1995 IEEE 21st International Conference on Industrial Electronics, Control, and Instrumentation, pp. 530535, November 1995.

[39] L. Idkhajine, E. Monmasson, M. W. Naouar, A. Prata, and K. Bouallaga, "Fully integrated FPGA-based controller for 
synchronous motor drive," IEEE Transactions on Industrial Electronics, vol. 56, no. 10, pp. 4006-4017, 2009.

[40] A. Lokriti, I. Salhi, and S. Doubabi, "IM Direct Torque Control with no flux distortion and no static torque error," ISA Transactions $^{\circledR}$, vol. 59, pp. 256-267, 2015.

[41] N. R. N. Idris, C. L. Toh, and M. E. Elbuluk, "A new torque and flux controller for direct torque control of induction machines," IEEE Transactions on Industry Applications, vol. 42, no. 6, pp. 1358-1366, 2006.

[42] A. Jidin, N. R. N. Idris, A. H. M. Yatim, T. Sutikno, and M. E. Elbuluk, "An optimized switching strategy for quick dynamic torque control in DTC-hysteresis-based induction machines," IEEE Transactions on Industrial Electronics, vol. 58, no. 8, pp. 3391-3400, 2011.

[43] B. Tabbache, M. Benbouzid, A. Kheloui, J.-M. Bourgeot, and A. Mamoune, "An improved fault-tolerant control scheme for PWM inverter-fed induction motor-based EVs," ISA Transactions $^{\circledR}$, vol. 52, no. 6, pp. 862-869, 2013.

[44] S. Rafa, A. Larabi, L. Barazane, M. Manceur, N. Essounbouli, and A. Hamzaoui, "Implementation of a new fuzzy vector control of induction motor," ISA Transactions ${ }^{\circledR}$, vol. 53, no. 3, pp. 744-754, 2014.

[45] E. Monmasson and M. N. Cirstea, "FPGA design methodology for industrial control systems - a review," IEEE Transactions on Industrial Electronics, vol. 54, no. 4, pp. 1824-1842, 2007.

[46] K. Jezernik, J. Korelič, and R. Horvat, "PMSM sliding mode FPGA-based control for torque ripple reduction," IEEE Transactions on Power Electronics, vol. 28, no. 7, pp. 3549-3556, 2013.

[47] T. Sutikno, N. R. N. Idris, A. Jidin, and M. N. Cirstea, "An improved FPGA implementation of direct torque control for induction machines," IEEE Transactions on Industrial Informatics, vol. 9, no. 3, pp. 1280-1290, 2013.

[48] J. C. Moctezuma, S. Sanchez, R. Alvarez, and A. Sanchez, "Architecture for filtering images using Xilinx system generator," in Proceedings of the 2nd WSEAS International Conference on Computer Engineering and Applications, World Scientific and Engineering Academy and Society (WSEAS), pp. 284-289, 2008.

[49] T. Saidani, M. Atri, D. Dia, and R. Tourki, "Using xilinx system generator for real time hardware co-simulation of video processing system," in Electronic Engineering and Computing Technology, vol. 60 of Lecture Notes in Electrical Engineering, pp. 227-236, Springer, Dordrecht, Netherlands, 2010.

[50] Xilinx, "Xilinx System Generator User's Guide," UG640 (v11.4), December 2009.

[51] Z. Maljković, M. Cettolo, and M. Pavlica, "The impact of the induction motor on short-circuit current," IEEE Industry Applications Magazine, vol. 7, no. 4, pp. 11-17, 2001.

[52] J. Soltani, G. R. A. Markadeh, N. R. Abjadi, and H. W. Ping, "A new adaptive direct torque control (DTC) scheme based-on SVM for adjustable speed sensorless induction motor drive," in Proceedings of the 30th Annual Conference of IEEE Industrial Electronics Society, 2004. IECON 2004, pp. 1111-1116, Busan, South Korea, 2004.

[53] H. F. Rashag, S. P. Koh, K. H. Chong, S. K. Tiong, N. M. L. Tan, and A. N. Abdalla, "High performance of space vector modulation direct torque control SVM-DTC based on amplitude voltage and stator flux angle," Research Journal of Applied Sciences, Engineering \& Technology, vol. 5, no. 15, pp. 3934-3940, 2013.
[54] K. Saber, G. Soufien, M. Abdellatif, and M. F. Mimouni, "A position control with a field programmable gate array-suntracking system for photovoltaic panels," Advances in System Dynamics and Control, pp. 192-231, 2018.

[55] Z. Zhang, R. Tang, B. Bai, and D. Xie, "Novel direct torque control based on space vector modulation with adaptive stator flux observer for induction motors," IEEE Transactions on Magnetics, vol. 46, no. 8, pp. 3133-3136, 2010.

[56] T. Von Raumer, J. M. Dion, L. Dugard, and J. L. Thomas, "Applied nonlinear control of an induction motor using digital signal processing," IEEE Transactions on Control Systems Technology, vol. 2, no. 4, pp. 327-335, 1994.

[57] Y. Utsumi, N. Hoshi, and K. Oguchi, "Comparison of FPGAbased direct torque controllers for permanent magnet synchronous motors," Journal of Power Electronics, vol. 6, pp. 114$120,2006$.

[58] A. Llor, B. Allard, X. Lin-Shi, and J. M. Retif, "Comparison of DTC implementations for synchronous machines," in Proceedings of the IEEE 5th Annual Power Electronics Specialists Conference, pp. 3581-3587, 2004.

[59] F. Bonnet, Contribution à l'Optimisation de la Commande d'une Machine synchrone à Double Alimentation utilisée en mode Moteur, Doctorat De L'Université De Toulouse, 2008.

[60] M. G. Shady, G. Damian, and W. F. John, "MRAS sensorless vector control of an induction motor using new sliding-mode and fuzzy-logic," IEEE Transactions On Energy Conversion, vol. 25, no. 2, pp. 394-402, 2010.

[61] M. O. Mahmoudi, N. Madani, M. F. Benkhoris, and F. Boudjema, "Cascade sliding mode control of a field oriented induction machine drive," The European Physical Journal Applied Physics, vol. 7, no. 3, pp. 217-225, 1999.

[62] S. Krim, S. Gdaim, A. Mtibaa, and M. F. Mimouni, "Modeling and hardware implementation on the FPGA of a variable structure control associated with a DTC-SVM of an induction motor," Electric Power Components and Systems, vol. 45, no. 16, pp. 1806-1821, 2017.

[63] M. F. Benkhoris and A. Gayed, "Discrete sliding control technique of DC motor drives," in Proceedings of the Sixth IEEE International Conference on Power Electronics and Variable Speed Drives, Septemper 1996.

[64] V. Utkin and J. Shi, "Integral sliding mode in systems operating under uncertainty conditions," in Proceedings of the 35th IEEE Conference on Decision and Control, pp. 4591-4596, Kobe, Japan, December 1996.

[65] Y. Pan, C. Yang, L. Pan, and H. Yu, "Integral sliding mode control: performance, modification, and improvement," IEEE Transactions on Industrial Informatics, vol. 14, no. 7, pp. 30873096, 2018.

[66] F. Barrero, A. González, A. Torralba, E. Galván, and L. G. Franquelo, "Speed control of induction motors using a novel fuzzy sliding-mode structure," IEEE Transactions on Fuzzy Systems, vol. 10, no. 3, pp. 375-383, 2002.

[67] A. Chalanga, S. Kamal, L. M. Fridman, B. Bandyopadhyay, and J. A. Moreno, "Implementation of super-twisting control: super-twisting and higher order sliding-mode observer-based approaches," IEEE Transactions on Industrial Electronics, vol. 63, no. 6, pp. 3677-3685, 2016.

[68] S. V. Emelyanov, S. K. Korovin, and A. Levant, "Higherorder sliding modes in control systems," Ordinary Differential Equations, vol. 29, no. 11, pp. 1627-1647, 1993. 
[69] L. Amet, M. Ghanes, and J.-P. Barbot, "HOSM control under quantization and saturation constraints: Zig-Zag design solutions," in Proceedings of the 51st IEEE Conference on Decision and Control, CDC 2012, pp. 5494-5498, USA, December 2012.

[70] G. Bartolini, A. Ferrara, A. Levant, and E. Usai, "On second order sliding mode controllers," in Variable Structure Systems, Sliding Mode and Nonlinear Control, vol. 247, pp. 329-350, Springer, London, UK, 1999.

[71] M. Rashed, K. B. Goh, M. W. Dunnigan, P. F. A. MacConnell, A. F. Stronach, and B. W. Williams, "Sensorless second-order sliding mode speed control of a voltage-fed induction-motor drive using nonlinear state feedback," IEE Proceedings-Electric Power Applications, vol. 152, no. 5, pp. 1127-1136, 2005.

[72] S. Benelghali, M. E. Benbouzid, J. F. Charpentier, T. AhmedAli, and I. Munteanu, "Experimental validation of a marine current turbine simulator: application to a permanent magnet synchronous generator-based system second-order sliding mode control," IEEE Transactions on Industrial Electronics, vol. 58, no. 1, pp. 118-126, 2011.

[73] M. Rafiq, S.-U. Rehman, F.-U. Rehman, Q. R. Butt, and I. Awan, "A second order sliding mode control design of a switched reluctance motor using super twisting algorithm," Simulation Modelling Practice and Theory, vol. 25, pp. 106-117, 2012.

[74] B. Nahid-Mobarakeh, F. Meibody-Tabar, and F.-M. Sargos, "Mechanical sensorless control of PMSM with online estimation of stator resistance," IEEE Transactions on Industry Applications, vol. 40, no. 2, pp. 457-471, 2004.

[75] M. Bendjedia, Y. Ait-Amirat, B. Walther, and A. Berthon, "Sensorless control of hybrid stepper motor," in Proceedings of the 2007 European Conference on Power Electronics and Applications, pp. 1-10, Aalborg, Denmark, September 2007.

[76] L. Idkhajine, E. Monmasson, and A. Maalouf, "Extended Kalman filter for AC drive sensorless speed controller - FPGAbased solution or DSP-based solution," in Proceedings of the 2010 IEEE International Symposium on Industrial Electronics, ISIE 2010, pp. 2759-2764, Bari, Italy, July 2010.

[77] M.-W. Naouar, E. Monmasson, A. A. Naassani, I. SlamaBelkhodja, and N. Patin, "FPGA-based current controllers for AC machine drives - a review," IEEE Transactions on Industrial Electronics, vol. 54, no. 4, pp. 1907-1925, 2007. 


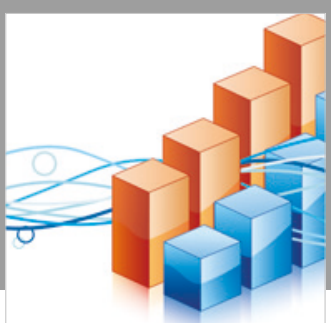

Advances in

Operations Research

\section{-n-m}
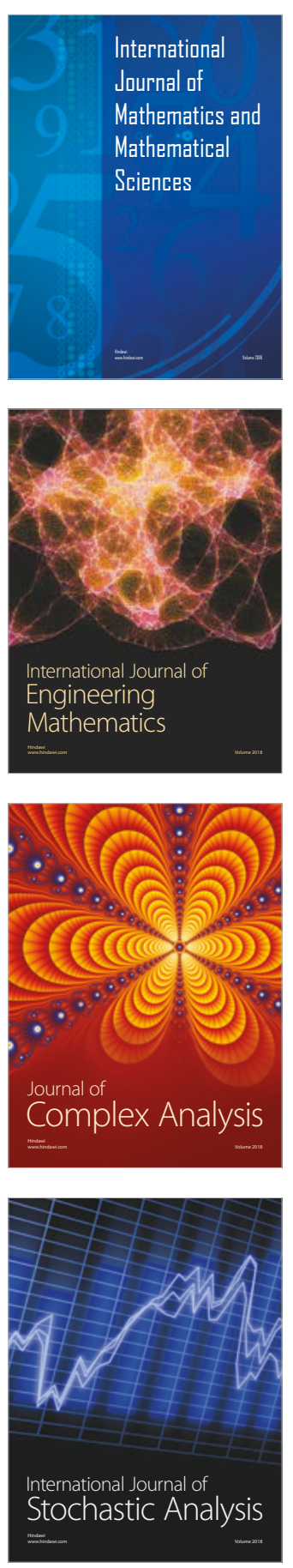
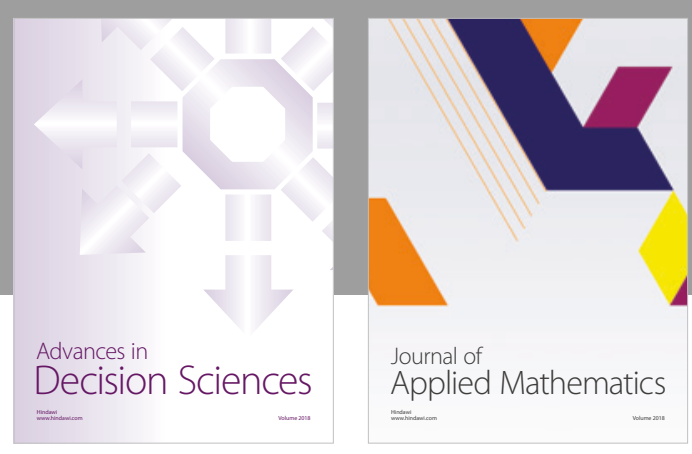

Journal of

Applied Mathematics
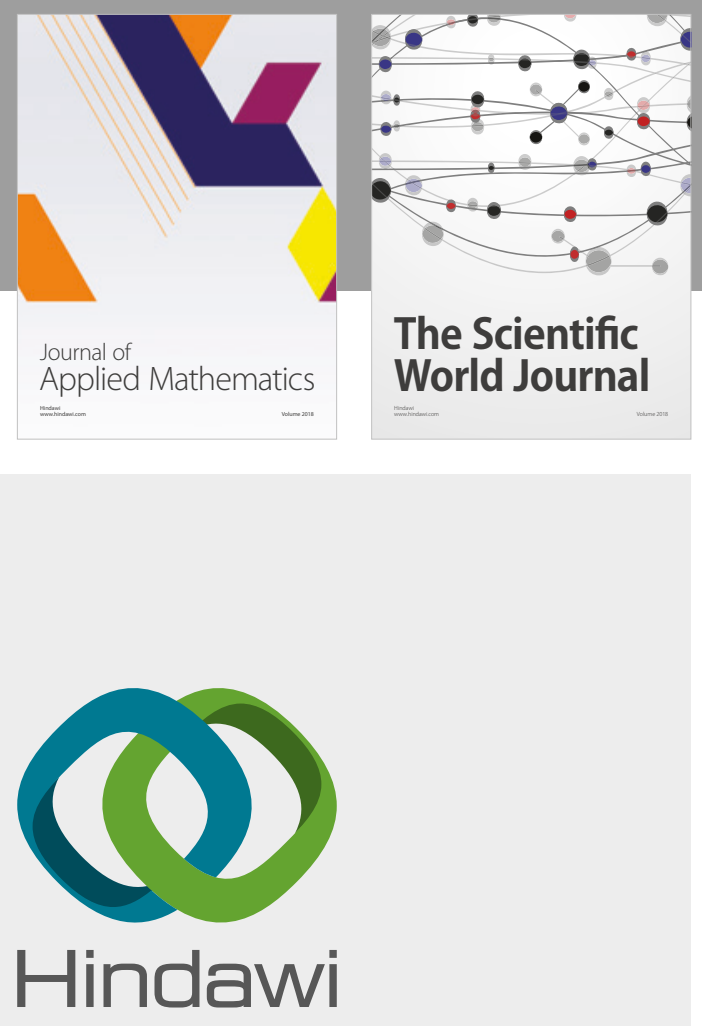

Submit your manuscripts at

www.hindawi.com

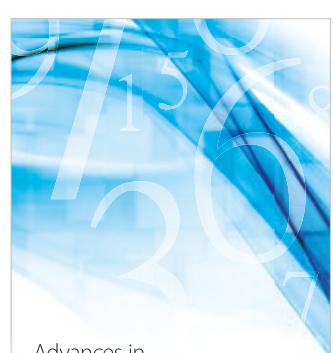

Advances in
Numerical Analysis
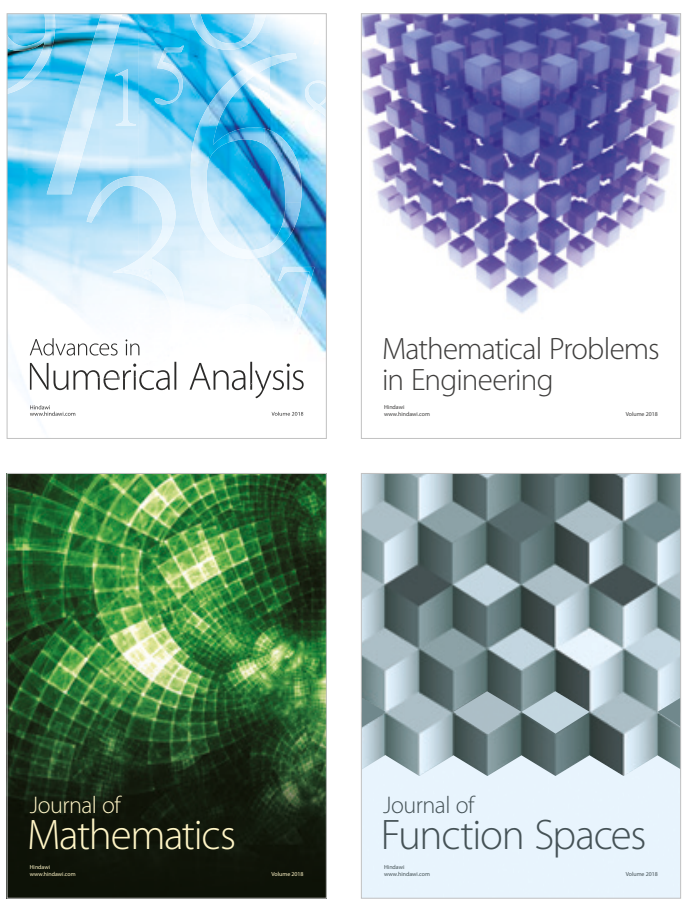

Mathematical Problems in Engineering

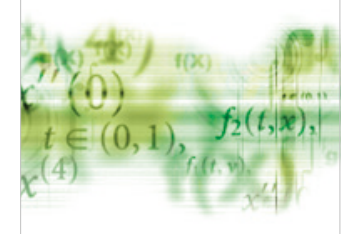

International Journal of

Differential Equations

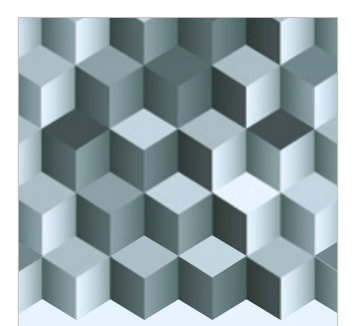

Journal of

Function Spaces
The Scientific

World Journal

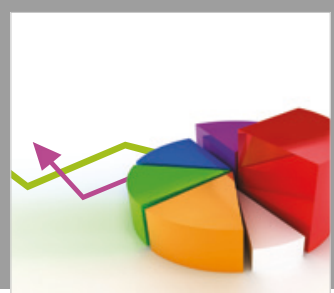

Journal of

Probability and Statistics
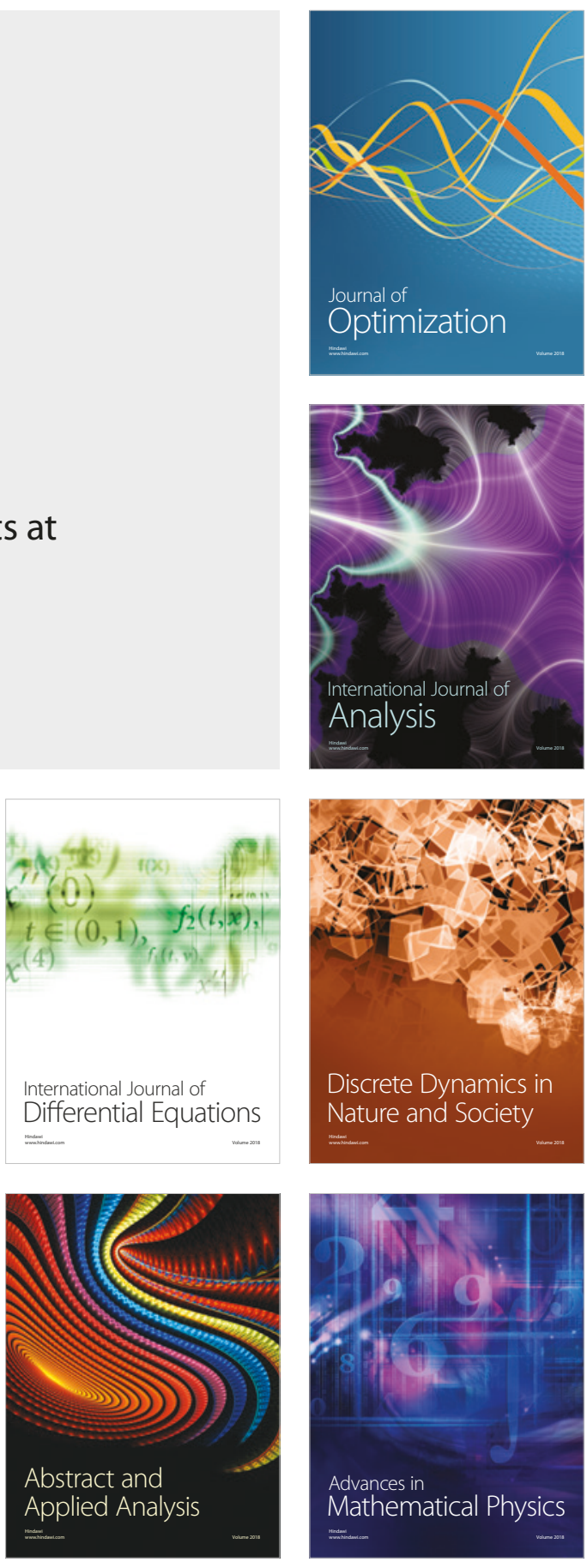